\title{
The Multi-Fungicide Resistance Status of Aspergillus fumigatus Populations in Arable Soils and the Wider European Environment
}

\author{
Bart Fraaije ${ }^{1,2 \star}$, Sarah Atkins ${ }^{2}$, Steve Hanley ${ }^{2}$, Andy Macdonald ${ }^{2}$ and John Lucas ${ }^{2}$ \\ ${ }^{1}$ NIAB, Cambridge, United Kingdom, ${ }^{2}$ Rothamsted Research, Harpenden, United Kingdom
}

The evolution and spread of pan-azole resistance alleles in clinical and environmental isolates of Aspergillus fumigatus is a global human health concern. The identification of hotspots for azole resistance development in the wider environment can inform

OPEN ACCESS

Edited by:

Ying-Chun Xu,

Peking Union Medical College

Hospital (CAMS), China

Reviewed by:

Hamid Badali,

The University of Texas Health Science Center at San Antonio, United States

Jochem B. Buil,

Radboud University Nijmegen Medical

Centre, Netherlands

Shallu Kathuria,

National Centre for Disease Control

(NCDC), India

${ }^{*}$ Correspondence:

Bart Fraaije

bart.fraaije@niab.com

Specialty section:

This article was submitted to Antimicrobials, Resistance and

Chemotherapy,

a section of the journal

Frontiers in Microbiology

Received: 26 August 2020 Accepted: 23 November 2020 Published: 15 December 2020

Citation:

Fraaije B, Atkins S, Hanley S, Macdonald $A$ and Lucas J (2020) The Multi-Fungicide Resistance Status of Aspergillus fumigatus Populations in Arable Soils and the Wider European Environment

Front. Microbiol. 11:599233. doi: 10.3389/fmicb.2020.599233 optimal measures to counteract further spread by minimizing exposure to azole fungicides and reducing inoculum build-up and pathogen dispersal. We investigated the fungicide sensitivity status of soil populations sampled from arable crops and the wider environment and compared these with urban airborne populations. Low levels of azole resistance were observed for isolates carrying the CYP51A variant F46Y/M172V/E427K, all belonging to a cluster of related cell surface protein (CSP) types which included t07, t08, t13, t15, t19, and t02B, a new allele. High levels of resistance were found in soil isolates carrying CYP51A variants $\mathrm{TR}_{34} / \mathrm{L} 98 \mathrm{H}$ and $\mathrm{TR}_{46} / \mathrm{Y} 121 \mathrm{~F} / \mathrm{T} 289 \mathrm{~A}$, all belonging to CSP types t01, t02, t04B, or t11. TR 46 Y121F/M172V/T289A/G448S (CSP t01) and $\mathrm{TR}_{46} / \mathrm{Y121F/T289A/S363P/I364V/G448S} \mathrm{(CSP} \mathrm{t01),} \mathrm{a} \mathrm{new} \mathrm{haplotype} \mathrm{associated} \mathrm{with}$ high levels of resistance, were isolated from Dutch urban air samples, indicating azole resistance evolution is ongoing. Based on low numbers of pan-azole resistant isolates and lack of new genotypes in soils of fungicide-treated commercial and experimental wheat crops, we consider arable crop production as a coldspot for azole resistance development, in contrast to previously reported flower bulb waste heaps. This study also shows that, in addition to azole resistance, several lineages of $A$. fumigatus carrying TR-based CYP51A variants have also developed acquired resistance to methyl benzimidazole carbamate, quinone outside inhibitor and succinate dehydrogenase (Sdh) inhibitor fungicides through target-site alterations in the corresponding fungicide target proteins; beta-tubulin (F200Y), cytochrome b (G143A), and Sdh subunit B (H270Y and H270R), respectively. Molecular typing showed that several multi-fungicide resistant strains found in agricultural soils in this study were clonal as identical isolates have been found earlier in the environment and/or in patients. Further research on the spread of different fungicide-resistant alleles from the wider environment to patients and vice versa can inform optimal practices to tackle the further spread of antifungal resistance in $A$. fumigatus populations and to safeguard the efficacy of azoles for future treatment of invasive aspergillosis.

Keywords: Aspergillus fumigatus, antifungal resistance, azoles, MBC fungicides, Qol fungicides, SDHI fungicides, environment 


\section{INTRODUCTION}

Aspergillus fumigatus is a mold commonly found on plant debris and in soil. It is also an opportunistic human pathogen causing allergic symptoms and life-threatening invasive infections. The incidence of invasive aspergillosis (IA) has been increasing in recent years largely due to increased numbers of immunocompromised individuals in the population unable to fight off infection. Treatment of IA is difficult as there are few effective antifungal drugs without toxic side-effects. Azoles are among the most widely used antifungals due to their efficacy and low toxicity. However, resistance to azoles has occurred in clinical isolates of $A$. fumigatus and is becoming more common, with potentially serious consequences for the treatment of invasive infections.

The first cases of azole resistance in A. fumigatus were reported in clinical strains from the USA isolated during the late 1980's (Denning et al., 1997). Recent studies have shown that resistance to medical azoles in both clinical and environmental isolates has increased in Europe and elsewhere since the late 1990's (Snelders et al., 2008; Howard et al., 2009). Azoles inhibit the enzyme sterol $14 \alpha$-demethylase (CYP51), a key step in the synthesis of sterols essential for the integrity of cell membranes. Aspergillus fumigatus has two CYP51 proteins, CYP51A and CYP51B. Many different resistant strains, mostly with CYP51A alterations, have been isolated from patients undergoing azole therapy (Howard et al., 2009). Other resistance mechanisms have also been found, including increased expression of CYP51 (Camps et al., 2012a,b; Buied et al., 2013) and efflux pump encoding genes (Fraczek et al., 2013; Meneau et al., 2016), accumulation of ergosterol precursors (Hagiwara et al., 2018; Rybak et al., 2019), and reduced intracellular retention of azoles (Wei et al., 2017).

Highly azole-resistant isolates have been found in the Netherlands in azole-naïve patients since 2007 (Van der Linden et al., 2011). These clinical strains and the majority of azoleresistant environmental isolates that have been characterized belong to two unique genotypes based on a combination of CYP51A alterations and promoter tandem repeat (TR) inserts of 34 or 46 bp. Clinical isolates carrying simultaneously CYP51A alterations $\mathrm{TR}_{34}$ and amino acid substitution $\mathrm{L} 98 \mathrm{H}\left(\mathrm{TR}_{34} / \mathrm{L} 98 \mathrm{H}\right)$ have been found in Europe since 1998 (Snelders et al., 2008; Lazzarini et al., 2016), whereas the first $\mathrm{TR}_{46} / \mathrm{Y} 121 \mathrm{~F} / \mathrm{T} 289 \mathrm{~A}$ isolate was reported from North America in 2008 (Wiederhold et al., 2016). These genotypes, which are now spread worldwide Verweij et al., 2016), are also highly resistant to several azole fungicides commonly used to preserve materials (e.g., wood, paints, and fabrics) and to prevent fungal diseases in animals, birds and plants. Subsequently, concerns have been raised about an environmental route of resistance selection through an unintended exposure of A. fumigatus as a non-target pathogen to azole fungicides in agricultural settings (Verweij et al., 2009; Berger et al., 2017; Hollomon, 2017). Detailed information on the origin and further spread of pan-azole resistant strains in the wider environment is therefore urgently needed (Chowdhary and Meis, 2018). This will enable thorough assessment of the extent of risk as predicted by Gisi (2014), and implementation of strategies to slow down and/or prevent future spread of azole resistance.
Flower bulb waste, green waste and wood chippings have recently been reported as "hotspots" for azole resistance development in the Netherlands (Schoustra et al., 2019). A hotspot is defined as a habitat that supports the growth and reproduction of $A$. fumigatus for relatively long periods of time in the presence of azole residues at concentrations that can select for resistant strains. This aim of this study is to investigate if fungicide applications on arable crops, particularly cereals, can be regarded as a hotspot for azole resistance development. Large amounts of fungicides are used to control diseases in cereals, including several triazoles that have been shown to have similar CYP51 binding modes and high levels of cross-resistance to medical azoles (Snelders et al., 2012). As such, living in agricultural areas was suggested to increase the risk of inhaling azole-resistant isolates (Rocchi et al., 2014). However, due to a low competitive ability of $A$. fumigatus to grow on straw in comparison with other saprophytic fungi, the low residue levels and short periods of bioavailability of azoles in soils after foliar spray applications, the risk of azole resistance development is estimated to be low (Gisi, 2014). Previous studies carried out with a limited number of samples and isolates suggest pan-azole resistance can be detected at low frequencies (2-3\%) in UK cereal fields (Bromley et al., 2014; Tsitsopoulou et al., 2018).

Having access to the long-term Park Grass (permanent grassland since 1856, no fungicides), as well as Broadbalk (continuous winter wheat since 1843) and two experiments examining the effects of repeatedly incorporating straw of continuous wheat crops at Rothamsted and Woburn with plots that have been sprayed with foliar fungicides or left untreated (Macdonald et al., 2018, enabled us to investigate if cereal foliar fungicide applications can select for resistance in $A$. fumigatus populations. For comparison, we also isolated and characterized $A$. fumigatus strains from air samples and soils of arable crops sampled at different locations in Europe using cell surface protein (CSP) sequence analysis (Klaassen et al., 2009) and microsatellite typing based on short tandem repeats (STRAf) (De Valk et al., 2005). The majority of strains were not only tested for sensitivity to several clinical and agricultural azoles but also to fungicides with different modes of action, including methyl benzimidazole carbamate (MBC), quinone outside inhibitor (QoI) and succinate dehydrogenase inhibitor (SDHI) fungicides, targeting beta-tubulin, cytochrome $b$ and succinate dehydrogenase ( $\mathrm{Sdh}$ ) subunits $\mathrm{B}, \mathrm{C}$, and $\mathrm{D}$, respectively. These fungicides are all commonly used to control diseases in arable crops and horticulture. An improved understanding of resistance development to different classes of fungicides in the environment can provide more information on the emergence and origin of novel resistant genotypes, and where and under which circumstances, selection is likely to occur in environmental and/or clinical settings.

\section{MATERIALS AND METHODS}

\section{Sampling of Soils}

Soil from Park Grass and some sections of Broadbalk have never been exposed to azole fungicides. Soils from other sections of Broadbalk have been annually exposed to single or multiple azole 
treatments since 1979. The amounts and identity of azoles used in seed treatments and foliar sprays reflect commercial practices and are recorded each year in the Results of the Classical and other Long-term Field Experiments available via the electronic Rothamsted Archive (http://www.era.rothamsted.ac.uk/eradoc/ book). During 2012-2015, prothioconazole was used in seed treatments and three azoles were applied in foliar sprays that were applied as part of a three-spray based disease management programme using mixtures of fungicides belonging to different mode of actions. Epoxiconazole, nine out of 12 applications, was most often used, followed by tebuconazole and prothioconazole, which were used three times together in a spray application. For this study, we sampled soil from plot $3 \mathrm{~d}$ (permanent pasture, receiving no fertilizers or chalk inputs) on Park Grass and from strips 2.2 (farmyard manure), 3 (no fertilizers), and 8 (144 kg N, $90 \mathrm{~kg} \mathrm{~K}$, and $12 \mathrm{~kg} \mathrm{Mg}$ per hectare) on sections 1 (with spring and summer fungicide treatments) and 6 (no fungicide treatments) under continuous winter wheat on Broadbalk (Macdonald et al., 2018). Soils were sampled to a depth of $5 \mathrm{~cm}$ using a $3 \mathrm{~cm}$ diameter auger at three sampling points, separated five meters apart, in July 2015. Samples of air-dried topsoil $(0-23 \mathrm{~cm})$ collected in August 2016 were also available from three replicated plots without straw incorporation (straw removed) and from three replicated plots in which fungicide-exposed straw was incorporated at four times the annual straw yield on the Longterm Amounts of Straw Experiments at Rothamsted and Woburn (Macdonald et al., 2018). These experiments examined the effects of long-term straw incorporation on soil properties and yields of continuous wheat grown on contrasting soils at Rothamsted and Woburn (silty clay loam v sandy loam). They began in 1987 and were stopped after 30 years (Powlson et al., 2011). The azole fungicides used in these experiments, as part of mixtures with other fungicides belonging to different modes of action, during 2013-2016 are listed in Table 1. The wheat seeds grown on these experiments were also treated with prothioconazole before drilling. Topsoil to a depth of $5 \mathrm{~cm}$ was also sampled from 15 commercial wheat fields in Germany (locations Burscheid, Vechta, Göttingen, Dormagen, and Ergolding), France (Tierce, Obenheim, Grisolles, Lignon, and Reims), and the UK (Kent, Suffolk, Somerset, Norfolk, and Herefordshire). In addition, topsoils representing arable crops, woodland, and grass verges were also sampled from 14 other locations in five countries across Europe (Table 2). Each topsoil sample contained three subsamples, each collected at three different sampling points separated at least $5 \mathrm{~m}$ apart.

\section{Sampling of Airborne A. fumigatus Strains}

Airborne spores were captured on untreated or fungicide amended Sabouraud dextrose (SD) agar (Oxoid Ltd, Basingstoke, $\mathrm{UK})$ containing penicillin $(100 \mathrm{U} / \mathrm{ml})$ and streptomycin $(100 \mu \mathrm{g} / \mathrm{ml})$ using mobile spin air samplers (IUL, Spain). Each time, 5,000 L of air was sampled during rotating of SD agar plates at $1 \mathrm{rpm}$ for $50 \mathrm{~min}$. Fungicide amended agar plates contained carbendazim $(10 \mu \mathrm{g} / \mathrm{ml})$, pyraclostrobin $(10 \mu \mathrm{g} / \mathrm{ml})$ or tebuconazole $(5 \mu \mathrm{g} / \mathrm{ml})$. Colonies of $A$. fumigatus were recovered from the plates after two days incubation at $48^{\circ} \mathrm{C}$.
TABLE 1 | The long-term amounts of straw experiments at Rothamsted and Woburn.

\begin{tabular}{|c|c|c|}
\hline $\begin{array}{l}\text { Location/foliar azole } \\
\text { exposure }\end{array}$ & $\begin{array}{l}\text { Straw } \\
\text { incorporation/plot } \\
\text { numbers }\end{array}$ & $\begin{array}{c}\text { Frequency pan-azole } \\
\text { resistant strains per } \\
\text { plot }^{\mathrm{a}}\end{array}$ \\
\hline Rothamsted farm & $\begin{array}{l}\text { Nil (straw } \\
\text { removed) }\end{array}$ & \\
\hline $\begin{array}{l}\text { Epoxiconazole (2013, } \\
2014,2015,2016)\end{array}$ & 1 & $0 / 7$ \\
\hline $\begin{array}{l}\text { Prochloraz (2014, } \\
\text { 2016) }\end{array}$ & 8 & $1 / 18$ \\
\hline $\begin{array}{l}\text { Prothioconazole (2013, } \\
2015,2016)\end{array}$ & 12 & $0 / 10$ \\
\hline \multirow[t]{4}{*}{$\begin{array}{l}\text { Tebuconazole (2013, } \\
\text { 2014, 2015, 2016) }\end{array}$} & $\begin{array}{l}\text { Four times amount } \\
\text { of straw }\end{array}$ & \\
\hline & 3 & $1 / 16$ \\
\hline & 5 & $0 / 14$ \\
\hline & 9 & 0/19 \\
\hline Woburn farm & $\begin{array}{l}\text { Nil (straw } \\
\text { removed) }\end{array}$ & \\
\hline $\begin{array}{l}\text { Epoxiconazole (2013, } \\
2014,2015,2016)\end{array}$ & 19 & $1 / 6$ \\
\hline Prochloraz (2015) & 21 & $0 / 8$ \\
\hline $\begin{array}{l}\text { Prothioconazole (2014, } \\
2015,2016)\end{array}$ & 28 & $1 / 10$ \\
\hline \multirow[t]{4}{*}{$\begin{array}{l}\text { Tebuconazole (2014, } \\
2015,2016)\end{array}$} & $\begin{array}{l}\text { Four times amount } \\
\text { of straw }\end{array}$ & \\
\hline & 20 & $0 / 5$ \\
\hline & 23 & $0 / 4$ \\
\hline & 27 & $0 / 5$ \\
\hline
\end{tabular}

Foliar exposure to azoles and the frequency of pan-azole resistant A. fumigatus isolates in soils sampled in 2016 .

${ }^{a}$ Pan-azole resistant $(R)$ strains have elevated MIC levels for voriconazole (>1.0 $\left.\mu \mathrm{g} / \mathrm{ml}\right)$, imazalil $(>2.5 \mu \mathrm{g} / \mathrm{ml})$, and tebuconazole $(>3.0 \mu \mathrm{g} / \mathrm{ml})$.

\section{Isolation of $A$. fumigatus Strains and Inoculum Preparation}

To isolate strains belonging to the A. fumigatus complex, $2 \mathrm{~g}$ aliquots of soil samples were added to $8 \mathrm{ml}$ of phosphate buffered saline amended with $0.1 \%(\mathrm{v} / \mathrm{v})$ Tween 20 . After $2 \mathrm{~h}$ incubation at $37^{\circ} \mathrm{C}$ with shaking (150 rpm), the supernatant after sedimentation was plated out on SD agar amended with penicillin $(100 \mathrm{U} / \mathrm{ml})$ and streptomycin $(100 \mu \mathrm{g} / \mathrm{ml})$. Colonies of $A$. fumigatus were recovered from the plates after 2 days incubation at $48^{\circ} \mathrm{C}$. No or low numbers up to 10 colony forming units per g soil were usually detected. After subculturing single colonies in tissue culture flasks with $12 \mathrm{ml} \mathrm{SD}$ agar for seven days at $37^{\circ} \mathrm{C}$, spores were harvested through shaking with $5 \mathrm{~mm}$ glass beads after addition of $3 \mathrm{ml}$ of saline. Final spore suspensions were directly used for storage in $50 \%(\mathrm{v} / \mathrm{v})$ glycerol at $-80^{\circ} \mathrm{C}$, DNA extractions or for fungicide sensitivity testing using spiral plating.

\section{Fungicide Sensitivity Testing Using Spiral Plating}

Spore suspensions containing $\sim 10^{6}$ spores $/ \mathrm{ml}$ in sterile distilled water were used in the microprocessor controlled Autoplate 
TABLE 2 | Soil samples from different geographical regions sampled in 2015 and the frequency of pan-azole resistant $A$. fumigatus strains.

\begin{tabular}{|c|c|c|c|}
\hline Sample & Location & Soil description & $\begin{array}{c}\text { Number of } \\
\text { pan-azole } \\
\text { resistant strains }\end{array}$ \\
\hline SS1 & $\begin{array}{l}\text { Penzesgyör, } \\
\text { Hungary }\end{array}$ & Wheat field & $0 / 10$ \\
\hline SS2 & Vönock, Hungary & Sunflower field & $0 / 10$ \\
\hline SS3 & Vönock, Hungary & Woodland & $0 / 10$ \\
\hline SS4 & Kenyeri, Hungary & Corn field & $0 / 14$ \\
\hline SS5 & $\begin{array}{l}\text { Kemmelbach, } \\
\text { Austria }\end{array}$ & Grass verge at petrol station & $0 / 12$ \\
\hline SS6 & $\begin{array}{l}\text { Hunderdorf, } \\
\text { Germany }\end{array}$ & Grass verge at petrol station & $0 / 10$ \\
\hline SS7 & $\begin{array}{l}\text { Hösbach, } \\
\text { Germany }\end{array}$ & Ploughed cereal field & $0 / 16$ \\
\hline SS8 & $\begin{array}{l}\text { Waremme, } \\
\text { Belgium }\end{array}$ & Sugar beet field & $1 / 10$ \\
\hline SS9 & $\begin{array}{l}\text { Adinkerke, } \\
\text { Belgium }\end{array}$ & Sugar beet field & $0 / 10$ \\
\hline SS10 & $\begin{array}{l}\text { Afferden, The } \\
\text { Netherlands }\end{array}$ & Corn field & $1 / 12$ \\
\hline SS11 & $\begin{array}{l}\text { Beekbergen, The } \\
\text { Netherlands }\end{array}$ & Forest & $0 / 10$ \\
\hline SS12 & $\begin{array}{l}\text { Boxtel, The } \\
\text { Netherlands }\end{array}$ & Forest & $0 / 10$ \\
\hline SS13 & $\begin{array}{l}\text { Boxtel, The } \\
\text { Netherlands }\end{array}$ & Harrowed sugar beet field & $0 / 10$ \\
\hline SS14 & $\begin{array}{l}\text { Boxtel, The } \\
\text { Netherlands }\end{array}$ & Corn field & $0 / 10$ \\
\hline
\end{tabular}

a Pan-azole resistant $(R)$ strains have elevated MIC levels for voriconazole $(>1.0 \mu \mathrm{g} / \mathrm{ml})$, imazalil $(>2.5 \mu \mathrm{g} / \mathrm{ml})$ and tebuconazole $(>3.0 \mu \mathrm{g} / \mathrm{ml})$.

Spiral Plating System AP5000 (Advanced Biosystems) according to the manufacturer's instructions. This method has been used for antimicrobial susceptibility testing of fastidious bacteria and fungi (Förster et al., 2004; Pong et al., 2010). The test fungicides, solutions made in DMSO, were placed in a sample cup of the spiral plater and automatically plated at exponentially decreasing concentrations achieving. Depending on the molecular weight of the compounds, an up to a 200-fold fungicide dilution gradient on SD agar was achieved using $15 \mathrm{~cm}$ plates. The concentration ranges $(\mu \mathrm{g} / \mathrm{ml})$ for the different fungicides were: boscalid (0.1-18.469), carbendazim (0.1-11.464), imazalil (0.25-43.153), itraconazole (0.025-6.113 or $0.1-22.324)$, pyraclostrobin $(0.1-$ 20.120), tebuconazole (0.1-17.349), terbinafine (0.01-1.7), and voriconazole $(0.1-19.120)$. The different concentration ranges were chosen to distinguish sensitive wild-type (wt) isolates without known resistance mechanisms with those of insensitive isolates harboring resistance mechanism in one assay. Isolates were streaked on these spiral SD agar plates ( 8 per plate) from the outside to the center using cotton swaps and incubated at $37^{\circ} \mathrm{C}$ in the dark. After $24 \mathrm{~h}$ incubation, the fungal growth of each isolate on the spiral plate was visually assessed and the MIC value determined using the Spiral Gradient Endpoint (SGE) software.

\section{DNA Extractions}

After harvesting spores from one-week cultures in tissue culture flasks, $1.5 \mathrm{ml}$ of spore suspensions was transferred into a $2 \mathrm{ml}$ tube and centrifuged for $2 \mathrm{~min}$ at 13,200 rpm. After removing the supernatant, DNA was extracted according to the MasterPure Yeast DNA Purification kit (Lucigen Corporation) with the inclusion of an extra bead-beating step which involved the addition of glass beads (0.425$0.600 \mathrm{~mm}$ ) and the use of the Genie 2 Vortex (Scientific Industries) at full power for $2 \mathrm{~min}$. This step was carried out after the lysis step just before adding the MPC Protein Precipitation Reagent.

\section{PCR Amplification and Sequencing}

All PCR reactions were carried out using the Easy A cloning Enzyme kit (Agilent Technologies, UK). Typical reactions of $40 \mu \mathrm{l}$ contained $4.0 \mu \mathrm{l}$ Easy A cloning buffer $(10 \mathrm{x}$ stock), $0.8 \mu \mathrm{l}$ dNTPs (10 mM stock), $30.4 \mu \mathrm{l}$ PCR grade water, $0.2 \mu \mathrm{l}$ of each of primer $(100 \mu \mathrm{M}$ primer stocks) (Supplementary Table 1), $0.4 \mu$ l Easy A cloning enzyme, and $4.0 \mu \mathrm{l}$ genomic DNA (40 ng total). PCR cycling started with an initial denaturation of $95^{\circ} \mathrm{C}$ for $2 \mathrm{~min}$, followed by 40 cycles of denaturation $\left(10 \mathrm{~s}\right.$ at $95^{\circ} \mathrm{C}$ ), annealing (20 s at annealing temperature) and extension (depending on amplicon size 1 or $2 \mathrm{~min}$ at $72^{\circ} \mathrm{C}$ ), and a final extension ( 8 or $9 \mathrm{~min}$ at $72^{\circ} \mathrm{C}$ ) and hold step at $4^{\circ} \mathrm{C}$. All primers and corresponding annealing temperatures are shown in Supplementary Table 1. PCR products were visualized by agarose gel electrophoresis to confirm the expected PCR amplicon size, and subsequently sent to MWG Eurofins (UK) for purification and sequencing using the primers used in PCR or with additional primers when needed (Supplementary Table 1). Primers used in this study were either reported before or designed based on published A. fumigatus sequences for CYP51A (Genbank Accession JX283445), CYP51B (AF338660), beta tubulin (NC_007200; region 70221-71948), cytochrome $b$ (JQ346808), and succinate dehydrogenase subunit B (NC_007194.1; region 2654821-2655836), C (NC_007198.1; region 2501949-2502752), and D (NC_007198.1; region 42150454215968) covering all regions of the fungicide target encoding genes where mutations affecting inhibitor binding have been reported (Mair et al., 2016). Sequences were analyzed and aligned using Geneious software version 10.0 (Biomatters, New Zealand).

\section{Short Tandem Repeat and Cell Surface Protein Typing}

Isolates of $A$. fumigatus with different levels of azole sensitivity were further characterized using microsatellite genotyping based on a panel of nine short tandem repeat markers (STRAf $2 \mathrm{~A}, 2 \mathrm{~B}, 2 \mathrm{C}, 3 \mathrm{~A}, 3 \mathrm{~B}, 3 \mathrm{C}, 4 \mathrm{~A}, 4 \mathrm{~B}$, and $4 \mathrm{C}$ ) according to the method previously described and validated (De Valk et al., 2005; De Groot and Meis, 2019). In addition, the cell surface protein (CSP) (XM_749624.1) encoding gene of A. fumigatus was also partially sequenced from selected strains (Balajee et al., 2007). CSP typing of strains was carried out according to the nomenclature proposed by Klaassen et al. (2009), 
which is based on the tandem repeat region, in which up to 10 different 12-bp repeat sequences have been found in different copy numbers, and the flanking regions. After manual alignment of sequences, a phylogenetic tree for the different CSP sequences encountered in this study was constructed using the Geneious Tree Builder software (Biomatters, New Zealand) based on the Tamura-Nei distance model and the NeighborJoining method.

\section{RESULTS}

\section{Isolation and Fungicide Sensitivity Testing of $A$. fumigatus Isolates From the Broadbalk and Park Grass Long-Term Experiments}

A total of 180 A. fumigatus strains were isolated from soils taken from selected plots on the Broadbalk Wheat Experiment, at Rothamsted (Harpenden, Hertfordshire, UK) (Macdonald et al., 2018). Soils were sampled from plots receiving three different fertilizer/manure treatments [plots 2.2 (farmyard manure), 3 (nil fertilizers), and 8 (mineral fertilizers)] within each of two sections under continuous winter wheat, grown with (section 1) and without (section 6) spring or summer fungicides, but including fungicide seed treatments. In addition, 30 strains were isolated from soils taken from the Park Grass Continuous Hay Experiment (permanent grass land, plot 3d - no liming and fertilizers) at Rothamsted (Macdonald et al., 2018). MIC testing using spiral plating showed for the wild-type (WT-NL), $\mathrm{TR}_{34} / \mathrm{L} 98 \mathrm{H}$ (TR34-NL), and $\mathrm{TR}_{46} / \mathrm{Y} 121 \mathrm{~F} / \mathrm{T} 289 \mathrm{~A}$ (TR46-NL) reference strains the following average values in $\mu \mathrm{g} / \mathrm{ml}: 0.338,0.180$, and 0.286 for terbinafine, $1.056,>6.113$, and $>6.113$ for itraconazole, $0.342,1.505$, and $>19.120$ for voriconazole, $0.978,3.156$, and $>43.153$ for imazalil, $0.829,6.876$, and $>17.349$ for tebuconazole, and 1.029, 1.048, and $>11.464$ for carbendazim, respectively. High levels of resistance to all four azoles and, unexpectedly, carbendazim were measured for the reference strain TR46-NL. Except for itraconazole, strain TR34-NL showed more moderate levels of resistance to azoles in comparison with strains WT-NL and TR46-NL, but similar levels of sensitivity to terbinafine were recorded in all reference strains. The Broadbalk and Park Grass isolates showed no significant differences in the sensitivity levels between the six different populations tested, with most isolates showing similar levels of control as the wild-type reference strain in typical dose-response curves (Figure 1). The dynamic range was $0.092-0.53,0.059$ $4.757,0.1-0.965,<0.249-1.622,0.198-3.341$, and $0.433-$ $1.453 \mu \mathrm{g} / \mathrm{ml}$ for terbinafine, itraconazole, voriconazole, imazalil, tebuconazole and carbendazim, respectively. Only two strains, sampled from section 1 plot 3 (isolate BB1-3-B9) and section 6 plot 8 (isolate $\mathrm{BB} 6-8-\mathrm{C} 7$ ) showed resistance to itraconazole (MICs $>6.113 \mu \mathrm{g} / \mathrm{ml}$ ) and tebuconazole (MICs of 4.227 and $4.755 \mu \mathrm{g} / \mathrm{ml}$ ) but not to voriconazole (MICs of 0.675 and $0.418 \mu \mathrm{g} / \mathrm{ml}$ ) and imazalil (MICs of 1.015 and $0.714 \mu \mathrm{g} / \mathrm{ml}$ ) in the first screen.

\section{Isolation and Fungicide Sensitivity Testing of $A$. fumigatus Isolates From the Long-Term Amounts of Straw Experiments at Rothamsted and Woburn}

In total 84 strains were isolated from the wheat straw incorporation experiment at Rothamsted, 35 came from three control plots (plots 1, 8, and 12) and 49 from three plots where straw was incorporated (plots 3, 5, and 9) (Table 1). The soils sampled at the Woburn Experimental Farm (Woburn, Bedfordshire) contained less strains and only 24 and 14 strains were isolated from untreated (plots 19, 21, and 28) and straw incorporated plots $(20,23$, and 27), respectively (Table 1). Fungicide sensitivity was carried out as before except itraconazole, for which a higher spiral plate concentration range of $0.1-22.324 \mu \mathrm{g} / \mathrm{ml}$ was used in subsequent studies. The sensitivity profiles were similar for all populations tested showing no differences between untreated and straw incorporated plots (Figure 2). A significant number of isolates, 18 out of 122 tested, were highly resistant to itraconazole with MIC values $>10 \mu \mathrm{g} / \mathrm{ml}$. Only four isolates, three from untreated plots (two at Woburn and one from Rothamsted), and one from a straw incorporated plot at Rothamsted, showed moderate to high levels of resistance to voriconazole, imazalil, and tebuconazole using cut-off MIC values of $1.0,2.5$, and $3.0 \mu \mathrm{g} / \mathrm{ml}$, respectively. Three of these isolates, RS3-3, WN19-3, and WN28-6, showing the highest MIC for all four azoles tested (all out of range), were also highly resistant to carbendazim with MIC values $>11.464 \mu \mathrm{g} / \mathrm{ml}$, which is similar to the profile of the $\mathrm{TR}_{46} / \mathrm{Y} 121 \mathrm{~F} / \mathrm{T} 289 \mathrm{~A}$ reference strain. A lower level of azole resistance was measured for the carbendazim sensitive isolate $\mathrm{RN} 18-8$ which has a similar sensitivity profile to the $\mathrm{TR}_{34} / \mathrm{L} 98 \mathrm{H}$ reference strain. All strains tested were sensitive to terbinafine, with MIC values between 0.041 and $0.322 \mu \mathrm{g} / \mathrm{ml}$.

\section{Isolation and Fungicide Sensitivity Testing of $A$. fumigatus Isolates From Soils of Commercial Wheat Fields in Germany, France, and the UK}

In total 428 strains were isolated, of which 149, 139 and 140 came from Germany (locations Burscheid, Vechta, Göttingen, Dormagen, and Ergolding) France (Tierce, Obenheim, Grisolles, Lignon, and Reims) and the UK (Kent, Suffolk, Somerset, Norfolk, and Herefordshire), respectively. Thirty strains were isolated from all locations with exception of Ergolding (29), Grisolles (29), Reims (10 because subsamples were pooled), and Suffolk (20, only two subsamples available). The fungicide sensitivity profiles of the populations were similar for all locations tested (Figure 3). All strains were sensitive to terbinafine having MIC values between 0.082 and $0.669 \mu \mathrm{g} / \mathrm{ml}$. A high number of isolates, 12 from Germany, 25 from France and 11 from the UK, showed MIC values $>10 \mu \mathrm{g} / \mathrm{ml}$ for itraconazole. Only a few strains showed low levels of resistance to voriconazole, imazalil and tebuconazole using cut-off MIC values of 1.0, 2.5, and $3.0 \mu \mathrm{g} / \mathrm{ml}$, respectively. Regarding voriconazole, only two 


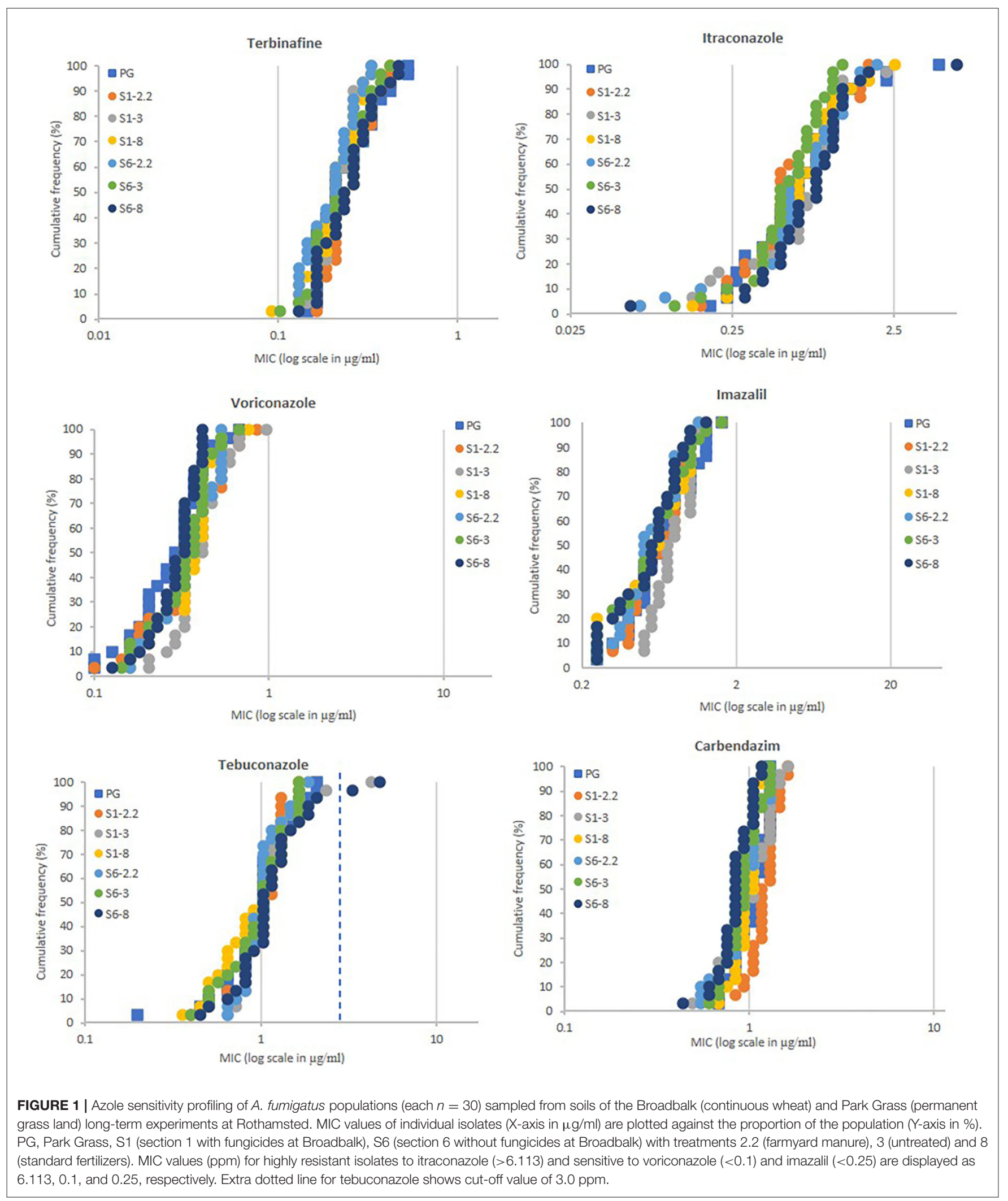




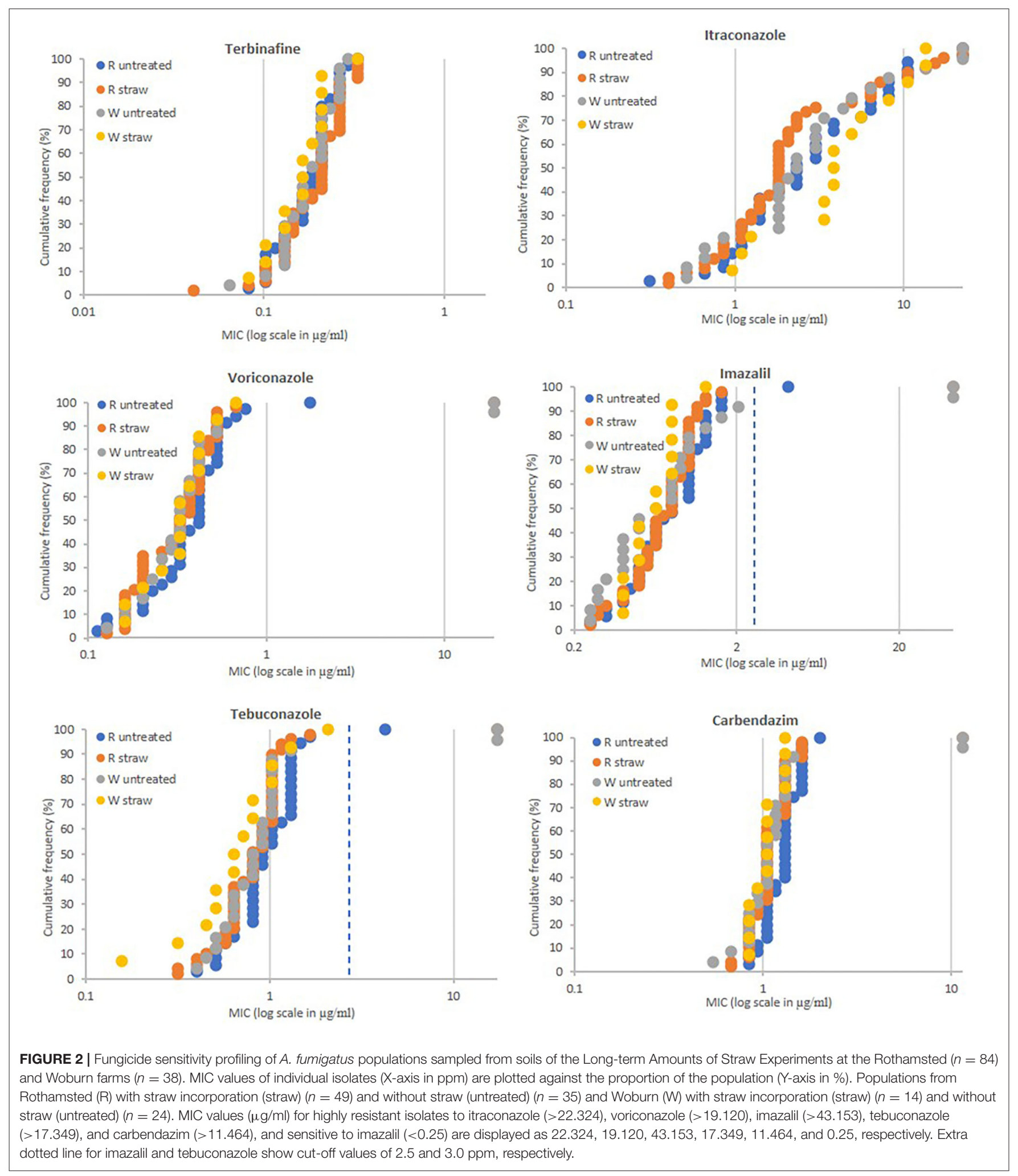

strains from Germany (G1-A1 and G1-A9 from Burscheid) and two from France (F1-C5 from Tierce and F5-B5 from Reims) showed low resistance levels with MICs between 1.0 and $2.0 \mu \mathrm{g} / \mathrm{ml}$. Two, three and four strains from Germany, France and the UK, respectively, were moderately resistant to imazalil with MICs between 2.5 and $5.0 \mu \mathrm{g} / \mathrm{ml}$. One, five and 

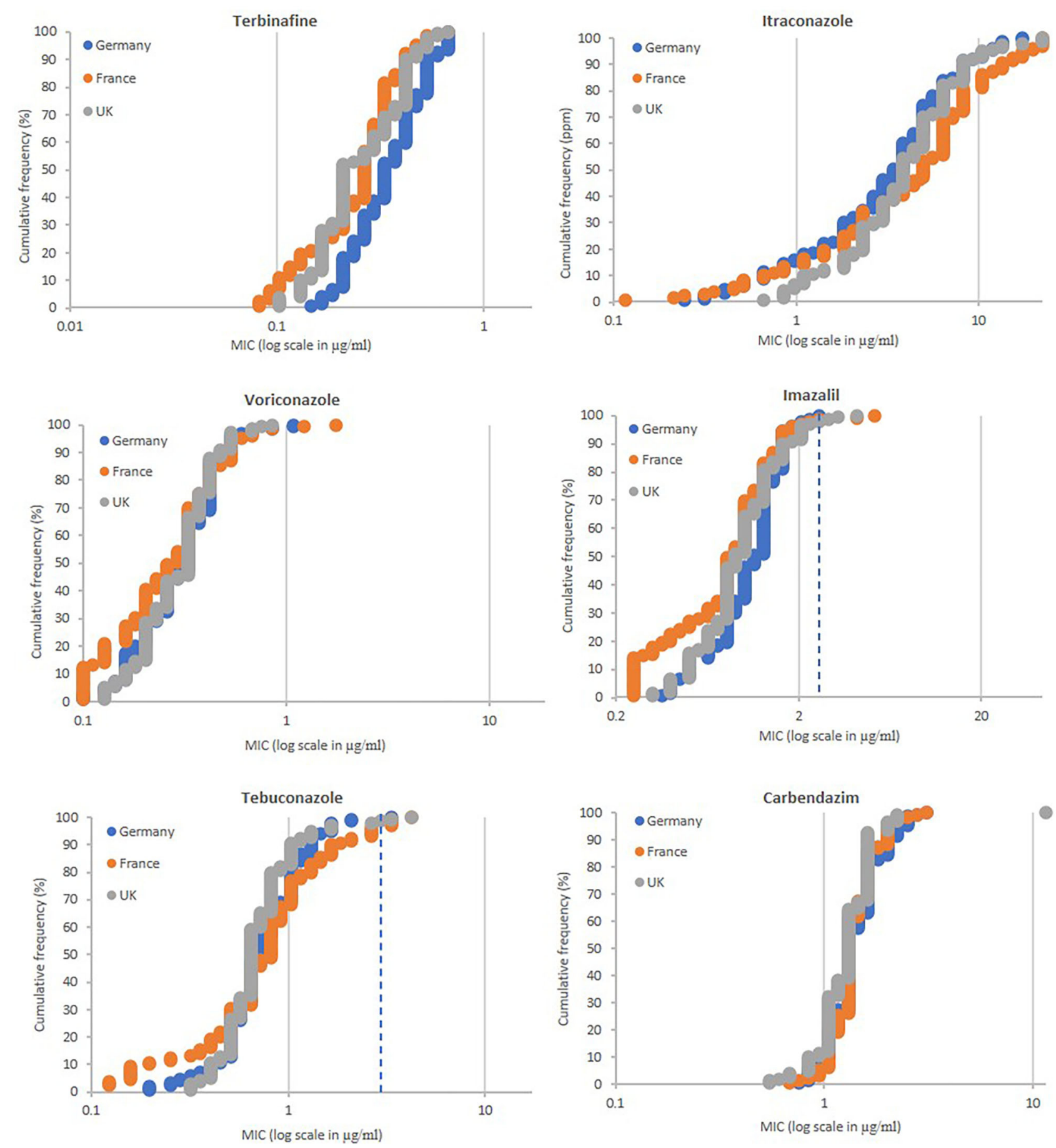

FIGURE 3 | Fungicide sensitivity profiling of $A$. fumigatus populations sampled from soils of commerial wheat fields in Germany $(n=149)$, France $(n=129)$, and the UK $(n=140)$. MIC values of individual isolates $(X$-axis in ppm) are plotted against the proportion of the population (Y-axis in \%). MIC values (ppm) for highly resistant isolates to itraconazole (>22.324) and carbendazim (>11.464) are displayed as 22.324 and 11.464, respectively. MIC values ( $\mu \mathrm{g} / \mathrm{ml})$ for highly resistant isolates to itraconazole (>22.324), voriconazole (>19.120), imazalil (>43.153), tebuconazole (>17.349), and carbendazim (>11.464), and sensitive to voriconazole $(<0.1)$ and imazalil $(<0.25)$ are displayed as $22.324,19.120,43.153,17.349,11.464,0.1$, and 0.25 , respectively. Extra dotted line for imazalil and tebuconazole show cut-off values of 2.5 and $3.0 \mathrm{ppm}$, respectively.

two strains from Germany, France and the UK, respectively, were moderately resistant for tebuconazole with MICs between 3.0 and $6.0 \mu \mathrm{g} / \mathrm{ml}$. None of the strains tested were resistant to all four azoles tested, but isolates UK5-B5 (Herefordshire, UK) and F1-C5 (Tierce, France), both highly resistant to itraconazole $(\mathrm{MIC}>22.324 \mu \mathrm{g} / \mathrm{ml})$ were the only strains showing 
resistance to two out of the three other azoles tested. UK5B5 was the only strain with resistance to carbendazim (MIC $>11.464 \mu \mathrm{g} / \mathrm{ml})$.

\section{Isolation and Fungicide Sensitivity Testing of $\boldsymbol{A}$. fumigatus Isolates From Soils at Different Locations in Europe}

Strains of $A$. fumigatus were isolated from soils sampled at 14 different locations in the Netherlands, Belgium, Germany, Austria and Hungary (Table 2). Ten or more strains per sample (154 strains in total) were further tested for sensitivity to terbinafine, itraconazole, voriconazole, imazalil, tebuconazole, and carbendazim (data not shown). All isolates were sensitive to terbinafine and carbendazim. Ten strains from locations in Hungary (Kenyeri), Austria (Kemmelbach), Germany (Hösbach), Belgium (Waremme), and the Netherlands (Afferden) showed itraconazole MICs $>10.0 \mu \mathrm{g} / \mathrm{ml}$, but only two of those strains, SS8-7 from a sugar beet field near Waremme in Belgium, and SS10-6 from a corn field near Afferden in the Netherlands, showed voriconazole MICs $>1.0 \mu \mathrm{g} / \mathrm{ml}$ and were also less sensitive to imazalil and tebuconazole with MICs just above 2.5 and $3.0 \mu \mathrm{g} / \mathrm{ml}$, respectively. Two strains from a sugar beet field near Adinkerke (Belgium) showed only a slightly raised MIC value of $3.341 \mu \mathrm{g} / \mathrm{ml}$ for tebuconazole. All other strains were sensitive to all azoles tested.

\section{Isolation and Fungicide Sensitivity Testing of $A$. fumigatus Isolates From Aerosols}

During 11-14 February 2018, 26-29 May 2018, and 17-20 May 2019, airborne spores were captured in Boskoop (the Netherlands), Boxtel (the Netherlands), or Harpenden (UK) on untreated and fungicide amended Sabouraud dextrose agar plates from air volumes of 5,000 L using mobile spin air samplers (IUL, Spain). Assuming an adult air intake of 14,000 L, the daily exposure to A. fumigatus varied between 14 and 193 conidia in Boskoop under cold and wet conditions in the afternoon on 11 February 2018 and in Boxtel during the evening on 20 February 2019, respectively. Only a few colonies were growing fast on tebuconazole amended plates on several occasions, which was compared to the recorded colony numbers on untreated plates equivalent to frequencies of up to $4 \%$.

Five isolates, captured on carbendazim amended agar in Boxtel (BTCa-1) and Boskoop (BKCb-1), tebuconazole amended agar in Boxtel (BTTa-1) and pyraclostrobin amended agar in Harpenden (HPPb-1 and $\mathrm{HPPb}-2$ ) in February 2018 were further tested for fungicide sensitivity. All five were highly resistant to both carbendazim and pyraclostrobin with MICs $>11.464$ and $>20.120 \mu \mathrm{g} / \mathrm{ml}$, respectively. BTTe-1 and BKCb1 were also highly resistant to imazalil (MIC $>43.153 \mu \mathrm{g} / \mathrm{ml}$ ), voriconazole $(\mathrm{MIC}>19.120 \mu \mathrm{g} / \mathrm{ml})$, and tebuconazole $(\mathrm{MIC}>17.349 \mu \mathrm{g} / \mathrm{ml})$, similar to the profile of the $\mathrm{TR}_{46} / \mathrm{Y} 121 \mathrm{~F} / \mathrm{T} 289 \mathrm{~A}$ reference strain. BTCa-1, HPPb-1, and HPPb-2 showed low to moderate levels of resistance to two or more of the azoles tested. All strains tested were sensitive to terbinafine with MICs between 0.116 and $0.595 \mu \mathrm{g} / \mathrm{ml}$.

\section{Cell Surface Protein Typing of $\boldsymbol{A}$. fumigatus Strains Isolated From the Long-Term Broadbalk and Park Grass Experiments}

A selection of isolates, 58 in total, was further characterized using cell surface protein (CSP) PCR amplicon sequencing (see primers in Supplementary Table 1). Figure 4 shows the relatedness amongst the different CSP types identified in this study. Of the 57 strains tested, 14 belonged to CSP type t03, 11t04A, 9-t18A, but they all came exclusively from a farm yard manure treated plot, 8-t02, 7-t01, 4-t05, 2-t06A, 2-t11, and one each to t08, t19 and a new CSP type. The new CSP type was named as $\mathrm{t} 02 *$ because the same tandem repeat succession as type t02 was found, but with changes in the flanking regions of the tandem repeat region at codon -14 (CTC instead of GTC), +1 (CCG instead of CCA), and +3 (CCT duplication) (Kidd et al., 2009). The itraconazole insensitive Broadbalk strains BB1-3-B9 and BB6-8-C7 belonged to CSP t02* and $\mathrm{t} 19$, respectively. When additional itraconazole insensitive isolates from commercial wheat fields in Germany, France and the UK were tested, a high proportion belonged to CSP $\mathrm{t} 08$, followed by $\mathrm{t} 13, \mathrm{t} 15, \mathrm{t} 19, \mathrm{t} 02^{*}$, and t07 (data not shown). All these CSP types cluster together and have also a SNP at codon-55 of the flanking region (TGT instead of TGC) in common (Figure 4).

\section{Azole Resistance Phenotype-to-Genotype Relationship of Isolates}

A selection of 30 azole insensitive and sensitive isolates, including six older reference strains, were further characterized using an additional genotyping assays and phenotyping screens (Tables 3, 4). Cross-resistance was observed for all four azoles tested, especially between voriconazole, tebuconazole and imazalil (Table 4). For itraconazole, two strains (BTTa-1 and $\mathrm{BKCb}-1$ ) highly insensitive for voriconazole, tebuconazole and imazalil showed only moderate levels of insensitivity to itraconazole, whereas several strains sensitive or moderately insensitive to voriconazole, tebuconazole, and imazalil (e.g., UK2-B4 and G1-A9) were highly insensitive to itraconazole. CYP51A sequencing showed a clear pheno-to-genotype trend, with $\mathrm{TR}_{46} / \mathrm{Y} 121 \mathrm{~F} / \mathrm{T} 289 \mathrm{~A}, \mathrm{TR}_{46} / \mathrm{Y} 121 \mathrm{~F} / \mathrm{M} 172 \mathrm{~V} / \mathrm{T} 289 \mathrm{~A} / \mathrm{G} 448 \mathrm{~S}$, and $\mathrm{TR}_{46} / \mathrm{Y} 121 \mathrm{~F} / \mathrm{T} 289 \mathrm{~A} / \mathrm{S} 363 \mathrm{P} / \mathrm{I} 364 \mathrm{~V} / \mathrm{G} 448 \mathrm{~S}$ isolates showing high levels of insensitivity to imazalil, voriconazole and tebuconazole (Table 4). Mutations leading to S363P (serine (TCT) replaced by proline (CCT) at codon 363) and I364V (isoleucine (ATT) replaced by valine (GTT) at codon 364) have not been reported before (see GenBank MW119308). Lower levels of insensitivity were measured for $\mathrm{TR}_{34} / \mathrm{L} 98 \mathrm{H}$ strains, while some strains carrying F46Y/M172V/E427K showed insensitivity to tebuconazole and/or itraconazole with MIC values $>3.0$ and $10 \mu \mathrm{g} / \mathrm{ml}$, respectively. D262Y was the only mutation found in sensitive strains. CYP51B sequencing of isolates BB1-3-B9, RN8-18, RS3-3, and WN19-9 revealed no mutations.

\section{Resistance to MBC, Qol, and SDHI Fungicides}

Insensitivity to carbendazim, pyraclostrobin and boscalid was also measured in a proportion of isolates (Table 4). All six 


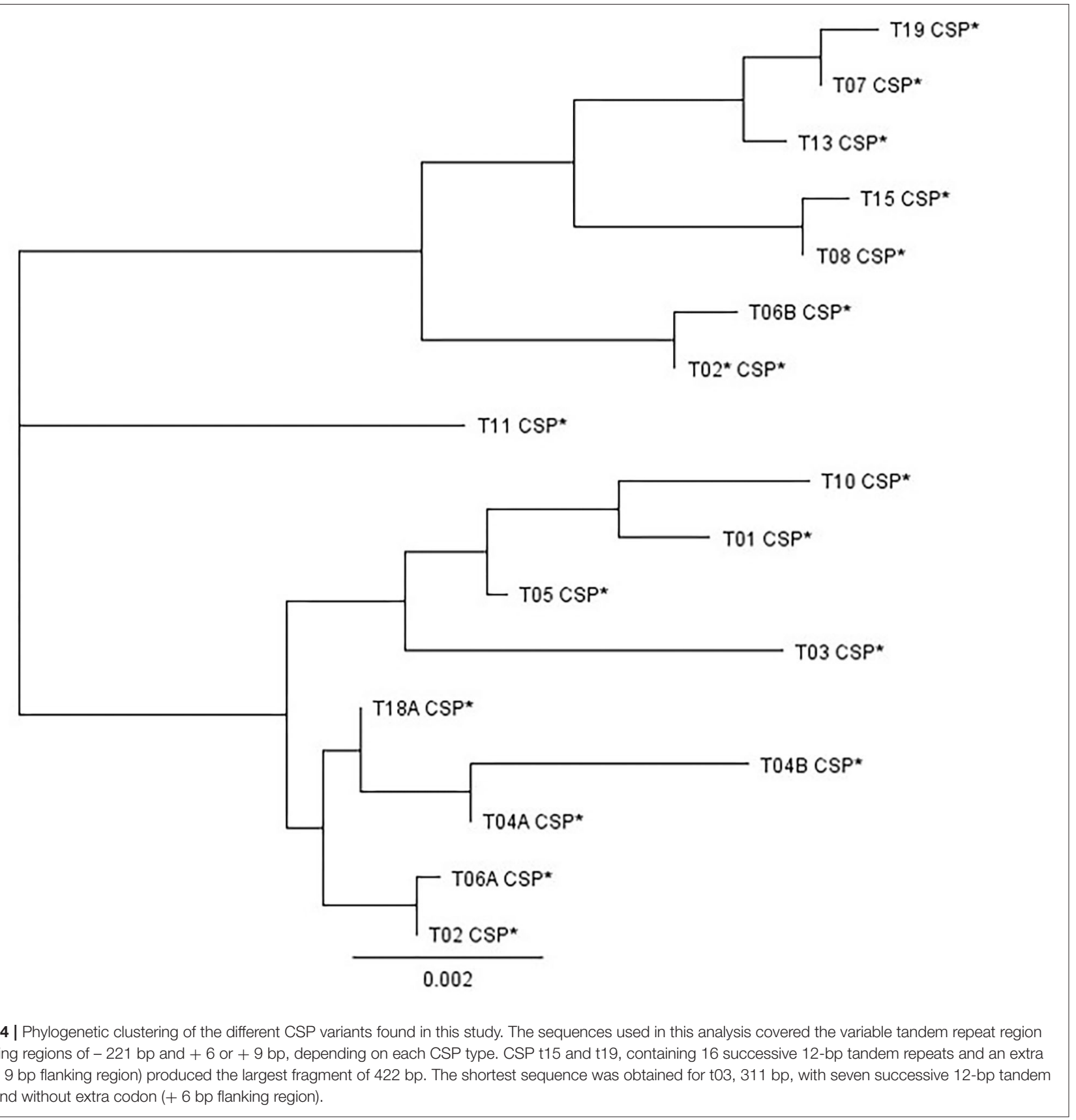

$\mathrm{TR}_{46}$ strains (TR46-NL included) were highly resistant to the MBC fungicide carbendazim (MIC $>11.464 \mu \mathrm{g} / \mathrm{ml}$ ), with five of them also resistant to the QoI fungicide pyraclostrobin (MIC > $11.464 \mu \mathrm{g} / \mathrm{ml}$ ). Two of these strains, BKCb-1 and WN19-3, were also moderately or highly resistant to the SDHI fungicide boscalid with MIC values of 5.606 and $>18.469 \mu \mathrm{g} / \mathrm{ml}$, respectively. Carbendazim, pyraclostrobin and boscalid resistance was also detected in several $\mathrm{TR}_{34}$ isolates but not in wild-type and F46Y/M172V/E427K isolates. Cytochrome $b$ gene sequence analysis (MW119309 and MW119310) showed the presence of a mutation leading to the replacement of glycine (GGT) by alanine (GCT) at codon 143 (G143A) of the protein in five pyraclostrobin resistant strains tested (UK5-B5, HPPb-1, BTTa-1, RS3-3, and WN19-3), all showing MICs $>20.120 \mu \mathrm{g} / \mathrm{ml}$. G143A was not detected in two pyraclostrobin sensitive strains (RN818 and $08-19-02-10)$ with MICs of 0.423 and $1.110 \mu \mathrm{g} / \mathrm{ml}$, respectively. Six carbendazim resistant isolates tested $(\mathrm{HPPb}-$ 1, BTTa-1, BKCb-1, RS3-3, WN19-3, and WN28-6), all with MICs $>11.464 \mu \mathrm{g} / \mathrm{ml}$, carried a mutation that resulted in the replacement of phenylalanine (TTC) by tyrosine (TAC) at codon 200 (F200Y) of beta-tubulin (MW119311 and MW119312). No target site alterations were found in the sequence of the 
TABLE 3 | Origin and characterization of Aspergillus fumigatus isolates using CYP51A sequencing, CSP typing, and STRAf profiling.

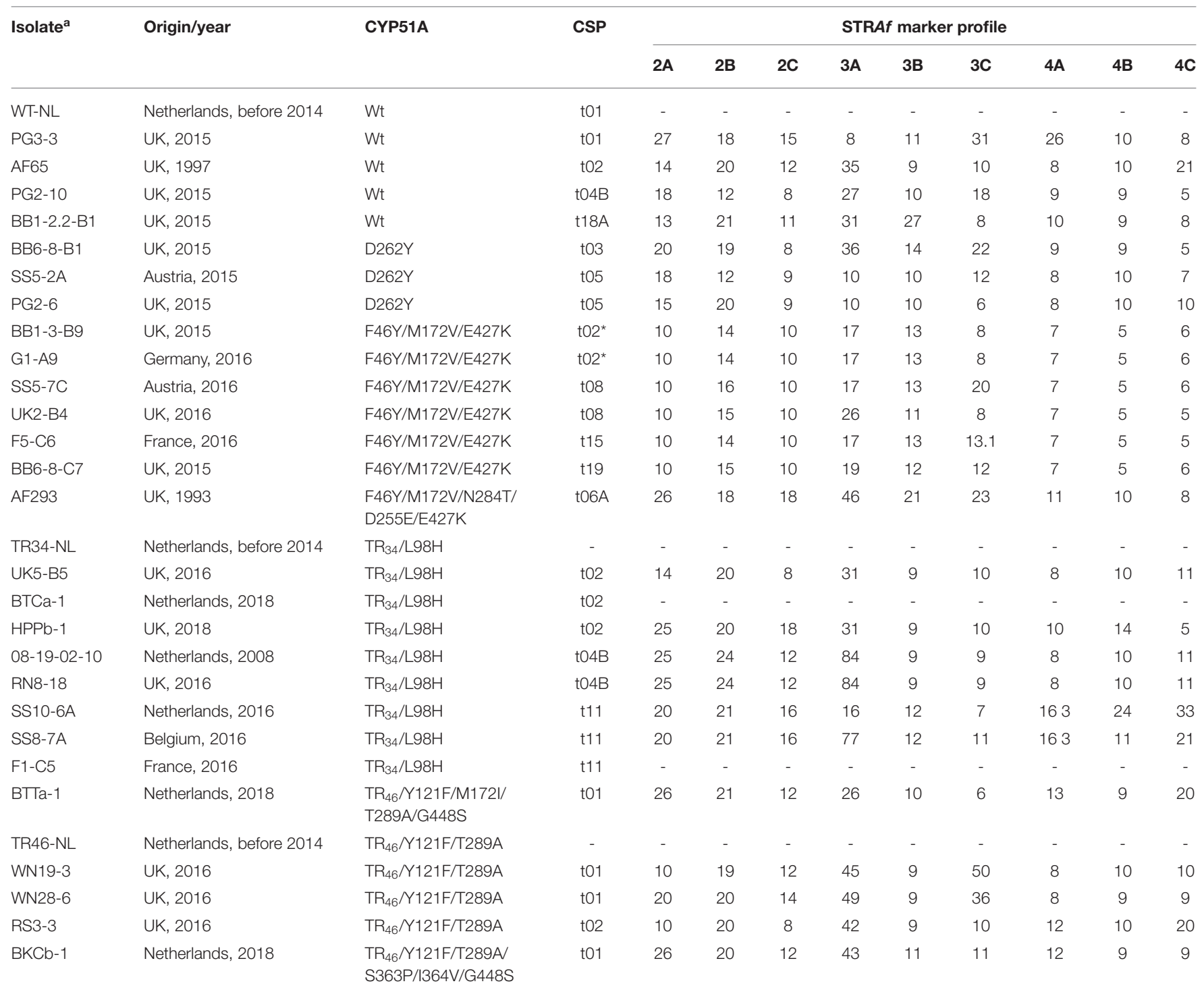

Isolates grouped according to CYP51A sequence and CSP type.

${ }^{a}$ AF65 and AF293 are clinical isolates; -, unknown or not determined.

carbendazim sensitive strain RN8-18 with a MIC of $1.048 \mu \mathrm{g} / \mathrm{ml}$. Only three out of 20 strains further characterized were insensitive to boscalid. Two strains, UK5-B5 and WN19-3, showed high levels of resistance with MICs $>18.469 \mu \mathrm{g} / \mathrm{ml}$, while strain BKCb-1 with a MIC of $5.606 \mu \mathrm{g} / \mathrm{ml}$ was moderately resistant. Sequencing the SdhB, C and D encoding genes from a boscalid sensitive (RN8-18), moderate resistant (BKCb-1) and highly resistant strain (WN19-3) revealed two different $S d h B$ mutations causing alterations at codon 270 of the protein (MW119305, MW119306, and MW119307). SdhB alteration H270Y, histidine (CAC) replaced by tyrosine (TAC) was found in WN19-3, while $\mathrm{H} 270 \mathrm{R}$, histidine (CAC) replaced by arginine (CGC) was identified in BKCb-1.

\section{Molecular Characterization of $A$. fumigatus Isolates Using CSP and STRAf Typing}

CSP typing showed a high level of diversity among the selected isolates (Table 3). Four CSP types, t02*, t08, t15, and t19, were detected in F46Y/M172V/E427K strains. In addition to these, we also found additional F46Y/M172V/E427K strains with CSP t07 or $\mathrm{t} 13$ as part of this study (data not shown). All these six CSP types are closely related (Figure 4). STRAf profiling showed that several markers were conserved (2A, 2C, $4 \mathrm{~A}$, and $4 \mathrm{~B}$ ) in all six F46Y/M172V/E427K strains that were further characterized (Table 3). CSP types t02, t04B, and $\mathrm{t} 11$ were detected in $\mathrm{TR}_{34} / \mathrm{L} 98 \mathrm{H}$ strains and $\mathrm{t} 01$ and t02 in $\mathrm{TR}_{46} / \mathrm{Y} 121 \mathrm{~F} / \mathrm{T} 289 \mathrm{~A}$ strains. The CSP types detected in 
TABLE 4 | CYP51A variants and sensitivity (MIC values in $\mu \mathrm{g} / \mathrm{ml}$ ) of Aspergillus fumigatus isolates to a panel of fungicides belonging to different modes of action.

\begin{tabular}{|c|c|c|c|c|c|c|c|c|c|}
\hline Isolate & Origin & IMA & VRC & TEB & ITC & TRB & CAR & PYR & BOS \\
\hline BB6-8-B1 & D262Y & 0.249 & 0.127 & 0.572 & 1.602 & 0.165 & 0.843 & 0.477 & - \\
\hline SS5-2A & D262Y & 0.398 & 0.531 & 0.318 & 0.666 & 0.295 & 1.619 & 0.375 & 0.199 \\
\hline BB1-2.2-B1 & Wt & 0.398 & 0.181 & 0.814 & 0.301 & 0.185 & 1.048 & 1.110 & 0.407 \\
\hline PG2-6 & D262Y & 0.447 & 0.230 & 0.198 & 0.266 & 0.165 & 0.843 & 0.423 & - \\
\hline WT-NL & Wt & 0.978 & 0.342 & 0.829 & 1.056 & 0.338 & 1.029 & 2.291 & 0.321 \\
\hline PG3-3 & Wt & 1.015 & 0.531 & 0.814 & 0.518 & 0.332 & 1.303 & 1.799 & 0.517 \\
\hline AF65 & $\mathrm{Wt}$ & 1.141 & 0.329 & 0.814 & 1.413 & 0.332 & 1.619 & 1.413 & 0.157 \\
\hline PG2-10 & Wt & 1.283 & 0.161 & 2.086 & 2.241 & 0.419 & 1.303 & - & - \\
\hline BB1-3-B9 & F46Y/M172V/E427K & 1.283 & 0.857 & 4.227 & 10.517 & 0.263 & 1.619 & 1.110 & 0.321 \\
\hline SS5-7C & F46Y/M172V/E427K & 1.620 & 0.418 & 1.649 & 3.401 & 0.263 & 1.619 & 1.413 & - \\
\hline BB6-8-C7 & F46Y/M172V/E427K & 1.622 & 0.531 & 1.466 & 3.856 & 0.295 & 0.609 & 1.413 & - \\
\hline G1-A9 & F46Y/M172V/E427K & 1.622 & 1.088 & 3.341 & 17.371 & 0.332 & 1.303 & 1.799 & - \\
\hline UK2-B4 & F46Y/M172V/E427K & 1.824 & 0.329 & 2.970 & $>22.324$ & 0.471 & 1.169 & 0.984 & 0.407 \\
\hline F5-C6 & F46Y/M172V/E427K & 2.306 & 0.531 & 2.086 & 8.184 & 0.419 & 1.619 & 1.799 & - \\
\hline AF293 & F46Y/M172V/N284T/D255E/E427K & 2.915 & 0.531 & 1.649 & 13.516 & 0.419 & 1.303 & 0.538 & - \\
\hline SS10-6A & $\mathrm{TR}_{34} / \mathrm{L} 98 \mathrm{H}$ & 2.915 & 1.381 & 4.227 & $>22.324$ & 0.208 & 1.303 & 0.231 & 0.321 \\
\hline SS8-7A & $\mathrm{TR}_{34} / \mathrm{L} 98 \mathrm{H}$ & 2.915 & 2.227 & 5.348 & $>22.324$ & 0.208 & 1.303 & 2.291 & 0.407 \\
\hline TR34-NL & $\mathrm{TR}_{34} / \mathrm{L} 98 \mathrm{H}$ & 3.156 & 1.505 & 6.876 & 7.219 & 0.180 & 1.048 & 0.872 & 0.224 \\
\hline 08-19-02-10 & $\mathrm{TR}_{34} / \mathrm{L} 98 \mathrm{H}$ & 3.277 & 1.754 & 5.348 & $>22.324$ & 0.208 & 1.619 & 1.110 & 0.407 \\
\hline F1-C5 & $\mathrm{TR}_{34} / \mathrm{L} 98 \mathrm{H}$ & 4.142 & 1.754 & 2.640 & $>22.324$ & 0.332 & 1.619 & 0.984 & 0.199 \\
\hline UK5-B5 & $\mathrm{TR}_{34} / \mathrm{L} 98 \mathrm{H}$ & 4.142 & 1.754 & 4.227 & $>22.324$ & 0.295 & $>11.464$ & $>20.120$ & $>18.469$ \\
\hline RN8-18 & $\mathrm{TR}_{34} / \mathrm{L} 98 \mathrm{H}$ & 4.142 & 1.754 & 4.227 & $>22.324$ & 0.103 & 1.048 & 0.423 & 0.407 \\
\hline BTCa-1 & $\mathrm{TR}_{34} / \mathrm{L} 98 \mathrm{H}$ & 5.236 & 0.857 & 3.341 & 4.955 & 0.595 & $>11.464$ & $>20.120$ & - \\
\hline HPPb-1 & $\mathrm{TR}_{34} / \mathrm{L} 98 \mathrm{H}$ & 5.236 & 3.591 & 5.348 & $>22.324$ & 0.165 & $>11.464$ & $>20.120$ & - \\
\hline ВТТ-1 & $\mathrm{TR}_{46} / \mathrm{Y121F} / \mathrm{M} 172 \mathrm{l} / \mathrm{T} 289 \mathrm{~A} / \mathrm{G} 448 \mathrm{~S}$ & $>43.153$ & $>19.120$ & $>17.349$ & 3.000 & 0.263 & $>11.464$ & $>20.120$ & 0.199 \\
\hline $\mathrm{BKCb}-1$ & $\mathrm{TR}_{46} / \mathrm{Y121F} / \mathrm{T} 289 \mathrm{~A} / \mathrm{S} 363 \mathrm{P} / \mathrm{I364V/G448S}$ & $>43.153$ & $>19.120$ & $>17.349$ & 1.100 & 0.116 & $>11.464$ & $>20.120$ & 5.606 \\
\hline TR46-NL & $\mathrm{TR}_{46} / \mathrm{Y121F} / \mathrm{T} 289 \mathrm{~A}$ & $>43.153$ & $>19.120$ & $>17.349$ & $>22.324$ & 0.286 & $>11.464$ & $>20.120$ & 0.407 \\
\hline RS3-3 & $\mathrm{TR}_{46} \mathrm{Y} 121 \mathrm{~F} / \mathrm{T} 289 \mathrm{~A}$ & $>43.153$ & $>19.120$ & $>17.349$ & $>22.324$ & 0.185 & $>11.464$ & $>20.120$ & 0.253 \\
\hline WN19-3 & $\mathrm{TR}_{46} / \mathrm{Y} 121 \mathrm{~F} / \mathrm{T} 289 \mathrm{~A}$ & $>43.153$ & $>19.120$ & $>17.349$ & $>22.324$ & 0.263 & $>11.464$ & $>20.120$ & $>18.469$ \\
\hline WN28-6 & $\mathrm{TR}_{46} / \mathrm{Y} 121 \mathrm{~F} / \mathrm{T} 289 \mathrm{~A}$ & $>43.153$ & $>19.120$ & $>17.349$ & $>22.324$ & 0.208 & $>11.464$ & 0.685 & 0.157 \\
\hline
\end{tabular}

Isolates ranked according to imazalil sensitivity (low to high MIC values).

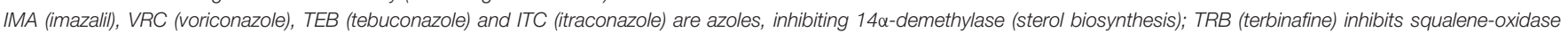

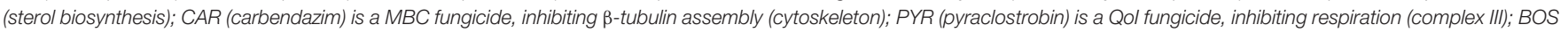
(boscalid) is a SDHI fungicide, inhibiting respiration (complex II); -, not determined.

the $\mathrm{TR}_{34} / \mathrm{L} 98 \mathrm{H}$ and $\mathrm{TR}_{46} / \mathrm{Y} 121 \mathrm{~F} / \mathrm{T} 289 \mathrm{~A}$ strains are different from those detected in F46Y/M172V/E427K strains and cluster together in one or two different groups with $\mathrm{t} 11$ separated (Figure 4). Two pairs of strains with identical CYP51A, CSP type, and STRAf profile were detected. BB-1-3-B9 and G1-A9 having F46Y/M172V/E427K, CSP t02* and STRAf profile [1014-10-17-13-8-7-5-6] in common, as well as mating type MAT11. $\mathrm{TR}_{34} / \mathrm{L} 98 \mathrm{H}$ strains $08-19-02-10$ and RN8-18 have STRAf profile [25-24-12-84-9-9-8-10-11] and have also CSP t04B and mating type MAT1-2 in common. $\mathrm{TR}_{34} / \mathrm{L} 98 \mathrm{H}$ strains SS10-6 and SSB8-7 carry both CSP $\mathrm{t} 11$ and have five out of nine STRAf markers identical.

\section{DISCUSSION}

Flower bulb waste, green waste and wood chippings have recently been reported as "hotspots" for azole resistance selection in the
Netherlands but more information on other hotspots will be needed to reduce the further selection and spread of fungicide resistant alleles. The aim of this study was to investigate if fungicide applications on cereals can be regarded as a hotspot for azole resistance selection.

None of the 180 strains isolated from soil samples at Broadbalk, taken from either untreated wheat crops $(n=90)$ or from plots sprayed with foliar fungicides $(n=90)$, tested positive for pan-azole resistant $\mathrm{TR}_{34}$ - or $\mathrm{TR}_{46}$-based CYP51A variants. Pan-azole resistant strains were also not detected amongst the 30 strains isolated from Park Grass experiment (permanent grass land). Furthermore, only two out of 418 strains $(0.5 \%)$ isolated from soils sampled from commercial wheat fields in France, Germany and the UK were pan-azole resistant. Both strains, one from France (F1-C5) and one from the UK (UK5-B5), carried $\mathrm{TR}_{34} / \mathrm{L} 98 \mathrm{H}$ (Table 3). Straw incorporation did not increase the incidence of pan-azole resistant strains in soil samples taken 
from winter wheat experiments carried out in Harpenden and Woburn (UK). Three strains [one $\mathrm{TR}_{34} / \mathrm{L} 98 \mathrm{H}$ (RN8-18) and two $\mathrm{TR}_{46} / \mathrm{Y} 121 \mathrm{~F} / \mathrm{T} 289 \mathrm{~A}$ (WN19-3 and WN28-6)] out of 59 isolates $(5.1 \%)$ were detected in soils from fungicide treated plots without straw incorporation, while only one $\mathrm{TR}_{46} / \mathrm{Y} 121 \mathrm{~F} / \mathrm{T} 289 \mathrm{~A}$ strain (RS3-3) out of 63 isolates (1.6\%) was found in soils of fungicide treated plots with straw incorporation. Only two out of 154 strains (1.3\%) sampled from grassland, forest and other arable crop soils in different European countries were pan-azole resistant. Both isolates, one from a Dutch corn field (SS10-6A) and one from a sugar beet field in Belgium (SS8$7 \mathrm{~A}$ ), carried $\mathrm{TR}_{34} / \mathrm{L} 98 \mathrm{H}$. Low frequencies of pan-azole resistant strains between 0 and $4.0 \%$ were found in air samples obtained at different urban locations in the Netherlands and the UK. This low background level of pan-azole resistant isolates in air samples is similar to the frequencies of resistant isolates found in soil samples of wheat crops but much lower than the frequencies reported for azole-containing flower bulb waste heaps (6.2-24.5\%), where high numbers of spores are present and can be released into the air (Schoustra et al., 2019). We also did not detect an impact of long-term azole-based foliar fungicide applications on the selection of resistant strains in the Broadbalk experiment, comparing treated with untreated plots, and conclude that cereal production is not a hotspot for azole resistance development in A. fumigatus as predicted by Gisi (2014).

In addition to wild-type, five different CYP51A variants were found in this study. Regarding azole sensitivity, variant D262Y was equally or less sensitive to azoles in comparison with wildtype isolates. Except itraconazole, for which different resistance mechanisms have been reported, $\mathrm{TR}_{46} / \mathrm{Y} 121 \mathrm{~F} / \mathrm{T} 289 \mathrm{~A}$ isolates showed higher levels or resistance to the azoles voriconazole, imazalil, and tebuconazole than $\mathrm{TR}_{34} / \mathrm{L} 98 \mathrm{H}$ isolates (Table 4). Similar patterns of MIC distributions to itraconazole and voriconazole have also been reported for wildtype, $\mathrm{TR}_{34} / \mathrm{L} 98 \mathrm{H}$ and $\mathrm{TR}_{46} / \mathrm{Y} 121 \mathrm{~F} / \mathrm{T} 289 \mathrm{~A}$ strains using methods described by the European Committee on Antimicrobial Susceptibility Testing (EUCAST) (van Ingen et al., 2015) and the Clinical and Laboratory Standards Institute (CLSI) M38-A2 document (Buil et al., 2018). A TR $46 / Y 121 \mathrm{~F} / \mathrm{M} 172 \mathrm{I} / \mathrm{T} 289 \mathrm{~A} / \mathrm{G} 448 \mathrm{~S}$ isolate (BTTa-1) and a $\mathrm{TR}_{46} / \mathrm{Y} 121 \mathrm{~F} / \mathrm{T} 289 \mathrm{~A} / \mathrm{S} 363 \mathrm{P} / \mathrm{I} 364 \mathrm{~V} / \mathrm{G} 448 \mathrm{~S}$ isolate (BKCb-1) were also found in this study. These more complex variants show similarities with the evolution of azole resistance in the plant pathogen Zymoseptoria tritici, where a stepwise accumulation of CYP51 mutations, determined by a negative trade-off between enzyme stability through reduced azole binding and enzyme functionality, has been reported to adapt to selection pressure exerted by different azoles entering and dominating the market (Cools and Fraaije, 2013). CYP51A amino acid substitutions Y121F, I364V, and G448S have homologous CYP51 position counterparts in other plant pathogens that have developed azole resistance (Mair et al., 2016). For example, G448S is equivalent to G460S in CYP51B of Pyrenopeziza brassicae conferring resistance to different azoles in this fungus (Carter et al., 2014). Mutations equivalent to Y121F and $\mathrm{I} 364 \mathrm{~V}$ have also evolved in Z. tritici (CYP51B Y137F and $\mathrm{I} 381 \mathrm{~V})$, conferring resistance to triadimenol and tebuconazole, respectively (Mullins et al., 2011; Cools and Fraaije, 2013). Modeling of the A. fumigatus CYP51A protein showed that S363 is one of the key residues anchoring the heme and, therefore, likely to affect azole binding (Fraczek et al., 2011), while other studies showed that I364 forms part of the azole binding pocket (Liu et al., 2016). As CYP51s are less conserved than other fungicide target proteins such as beta-tubulin and cytochrome $b$, in vitro gene modification techniques can be undertaken to establish the precise impact of single and multiple target-site changes on inhibitor binding.

In addition to pan-azole resistant $\mathrm{TR}_{34}$ and $\mathrm{TR}_{46}$ strains, a proportion of strains isolated from the different soil samples showed high MIC values for itraconazole and, often, also elevated MICs for tebuconazole and, to a lesser extent, imazalil and voriconazole (Table 4). F46Y/M172V/E427K was identified in most of these strains and this variant has been reported for both clinical and environmental strains in Europe and Australia since 2001 (Garcia-Rubio et al., 2018). F46Y/M172V/E427K isolates are generally not considered resistant (RodriguezTudela et al., 2008), but resistant isolates exceeding the EUCAST susceptibility break points for itraconazole $(2.0 \mu \mathrm{g} / \mathrm{ml})$, voriconazole $(2.0 \mu \mathrm{g} / \mathrm{ml})$, and/or posaconazole $(0.25 \mu \mathrm{g} / \mathrm{ml})$ have been reported in other studies (Howard et al., 2009; GarciaRubio et al., 2018). One new CSP variant t02* was found in this study. This new type, only found in F46Y/M172V/E427K isolates so far, can be distinguished from $\mathrm{t} 02$ by its flanking sequences (Figure 4). Based on the current nomenclature describing 29 different CSP types (Duarte-Escalante et al., 2020), t02 can be renamed as $\mathrm{t} 02 \mathrm{~A}$ and $\mathrm{t} 02^{*}$ as $\mathrm{t} 02 \mathrm{~B}$. All F46Y/M172V/E427K strains carried closely related CSP types, t02*, t08, t13, t15, and t19 (Figure 4), and had identical or similar STRAf profiles (Table 3), indicating a separate lineage or cryptic sister species as suggested in other studies using whole genome sequencing (Garcia-Rubio et al., 2018). We recently established that strain IMI 16152 (NRRL 163), isolated in 1911 from chicken lung by C. Thom (Peterson, 1992), is also carrying CYP51A F46Y/M172V/E427K. Because of its presence long before the introduction of azole fungicides in both agricultural and clinical settings in the 1970's and early 1980's (Maertens, 2004; Russell, 2005), respectively, we consider F46Y/M172V/E427K as an example of standing variation rather than acquired resistance.

Acquired resistance against azoles can take place both in patient and in agricultural settings in response to exposure to azole compounds (Hagiwara et al., 2016). The genetic variation measured among $\mathrm{TR}_{34} / \mathrm{L} 98 \mathrm{H}$ and $\mathrm{TR}_{46} / \mathrm{Y} 121 \mathrm{~F} / \mathrm{T} 289 \mathrm{~A}$ isolates has been less in comparison with wild-type isolates indicating single recent origins of the resistant genotypes (Snelders et al., 2008; Chowdhary et al., 2013). Although A. fumigatus can undergo asexual, parasexual and sexual stages, some populations, including a lineage harboring $\mathrm{TR}_{34} / \mathrm{L} 98 \mathrm{H}$ isolates, seem to reproduce predominantly asexually (Klaassen et al., 2012). A close association with CSP types and isolates carrying CYP51A $\mathrm{TR}_{34} / \mathrm{L} 98 \mathrm{H}$ (CSP t02, t03, t04A, t04B, and t11) or $\mathrm{TR}_{46} / \mathrm{Y} 121 \mathrm{~F} / \mathrm{T} 289 \mathrm{~A}$ (CSP t01, t02, and t04A) was also observed in other studies (Camps et al., 2012b; Bader et al., 2015). The presence of identical clones in different countries supports clonal expansion of resistant genotypes over long distances by 
airborne dispersal and/or transport of colonized agricultural produce (Chowdhary et al., 2012; Dunne et al., 2017; Sewell et al., 2019). Two identical clones were found in this study based on STRAf profiling (Table 3). One clone represented by isolates $\mathrm{BB}-1-3-\mathrm{B} 9$ and G1-A9, originating from wheat fields in the UK and Germany, respectively, have also MAT1-1, CSP type $\mathrm{t} 02^{*}$, and F46Y/M172V/E427K in common, and showed a close resemblance to Danish clinical F46Y/M172V/E427K and $\mathrm{TR}_{120} / \mathrm{F} 46 \mathrm{Y} / \mathrm{M} 172 \mathrm{~V} / \mathrm{E} 427 \mathrm{~K}$ strains with only one out of nine STRAf markers different (14 instead of 13 at 2B) (Hare et al., 2019). The other clone was formed by isolate RN8-18, isolated from a wheat field in the UK, and reference strain 08-1902-10, a Dutch environmental isolate from 2008 (Abdolrasouli et al., 2015), with also $\mathrm{TR}_{34} / \mathrm{L} 98 \mathrm{H}$, CSP t04B, and MAT1-2 in common. $\mathrm{TR}_{34} / \mathrm{L} 98 \mathrm{H}$ strain HPPB-1, isolated from an UK air sample, is very similar to an Australian clinical $\mathrm{TR}_{34} / \mathrm{L} 98 \mathrm{H}$ strain isolated in 2012 (Kidd et al., 2015) with only one STRAf marker different (19 for 18 at 2C). A clonal expansion based on an identical STRAf profile was also found for $\mathrm{TR}_{46} / \mathrm{Y} 121 \mathrm{~F} / \mathrm{T} 289 \mathrm{~A}$ strain RS3-3, sampled from an UK wheat field, matching with a German clinical $\mathrm{TR}_{46} / \mathrm{Y} 121 \mathrm{~F} / \mathrm{T} 289 \mathrm{~A}$ isolate dating back to 2012 (Steinmann et al., 2015) and several French clinical $\mathrm{TR}_{46} / \mathrm{Y} 121 \mathrm{~F} / \mathrm{T} 289 \mathrm{~A}$ strains in 2013 (Lavergne et al., 2015). With exception of STRAf marker 3C (21 instead of 22), one of the two markers for which low levels of instability have recently been reported (De Groot and Meis, 2019), soil isolates from India carrying $\mathrm{TR}_{46} / \mathrm{Y} 121 \mathrm{~F} / \mathrm{T} 289 \mathrm{~A}$ also showed the same profile as RS3-3 (Steinmann et al., 2015).

In addition to azoles, resistance to $\mathrm{MBC}$, QoI, and SDHI fungicides, commonly used in agriculture and, with exception of SDHIs, also for material preservation but not in clinical settings, was also detected in several pan-azole resistant isolates (Table 4). This confirms that $A$. fumigatus as a non-target organism can evolve acquired resistance to agricultural fungicides in the environment. Selection for MBC resistance is currently expected to be minimal for cereal production because the use of this fungicide group as seed treatment or in foliar spray applications in the UK has been very low since 2006 due to resistance development in a range of target pathogens (Hawkins and Fraaije, 2018). All six $\mathrm{TR}_{46}$ and three out of nine $\mathrm{TR}_{34}$ strains tested (reference strains included) showed high levels of resistance to carbendazim associated with beta-tubulin F200Y, a mutation commonly found in other plant pathogens that have evolved resistance to $\mathrm{MBC}$ fungicides after exposure (Hawkins and Fraaije, 2016; Mair et al., 2016). In contrast to beta-tubulin E198A, which is associated with high levels of resistance to carbendazim but sensitivity to the N-phenyl carbamate diethofencarb in several plant pathogens, F200Y confers resistance to both carbendazim and diethofencarb (Koenraadt et al., 1992). While the use of carbendazim as a plant protection product is no longer authorized in the EU, selection for $\mathrm{MBC}$ resistance can further occur elsewhere and in areas of crop protection where thiabendazole and thiophanate-methyl, which is degraded to carbendazim, are used. Diethofencarb has been used for treatment of flower bulbs to control Penicillium sp. and is still being used in foliar sprays to control diseases like Botrytis sp. in fruit and vegetables. Most of MBC-resistant $A$. fumigatus strains were also resistant to pyraclostrobin and this was linked to the presence of cytochrome $b$ G143A, a mutation associated with field resistance to QoI fungicides in a range of plant pathogens (Gisi et al., 2002). Only three strains showed insensitivity to boscalid. SdhB H270Y was detected in a strain highly resistant to boscalid (WN19-3; MIC >18.469 $\mu \mathrm{g} / \mathrm{ml}$ ), whereas SdhB H270Y was detected in a strain with moderate levels of boscalid resistance (BKCb- 1 MIC $=5.606 \mu \mathrm{g} / \mathrm{ml}$ ). Many different mutations can evolve after exposure to SDHI fungicides in experimental evolution experiments with fungi, including $Z$. tritici (Fraaije et al., 2012), and orthologous mutations to both SdhB H270Y and H270R have been reported in resistant field isolates of several plant pathogens, including Botrytis sp. on strawberries and tulips, Alternaria alternata on almonds and Stemphylium botryosum on asparagus (Sierotzki and Scalliet, 2013; Mair et al., 2016). Broad spectrum azole, MBC, QoI, and SDHI fungicides were introduced into the market in 1973, 1976, 1992, and 2003, respectively (Russell, 2005; Sierotzki and Scalliet, 2013). Isolates with resistance to multiple groups of fungicides have an advantage in habitats where there is abundant growth and sporulation in the presence of different fungicides such as compost and flower bulb waste heaps, and stockpiles of other fungicide-containing plant waste, the so called hotspots (Zhang et al., 2017; Schoustra et al., 2019). Favorable environmental conditions for the sexual stage can occur during composting and new azole resistant genotypes have been detected as well in this environment in the Netherlands. These included $\mathrm{TR}_{46} / \mathrm{Y} 121 \mathrm{~F} / \mathrm{T} 289 \mathrm{~A} / \mathrm{I} 364 \mathrm{~V}, \mathrm{TR}_{46} / \mathrm{Y} 121 \mathrm{~F} / \mathrm{M} 172 \mathrm{I} / \mathrm{T} 289 \mathrm{~A} / \mathrm{G} 448 \mathrm{~S}$, a variant reported in the Netherlands in 2010 (Zhang et al., 2017) and recently in Iran (Ahangarkani et al., 2020), and $\mathrm{TR}_{46}^{2} / \mathrm{Y} 121 \mathrm{~F} / \mathrm{M} 172 \mathrm{I} / \mathrm{T} 289 \mathrm{~A} / \mathrm{G} 448 \mathrm{~S}$ and $\mathrm{TR}_{46}^{3} / \mathrm{Y} 121 \mathrm{~F} / \mathrm{M} 172 \mathrm{I} / \mathrm{T} 289 \mathrm{~A} / \mathrm{T} 289 \mathrm{~A} / \mathrm{G} 448 \mathrm{~S}$, multiple 46bp promoter repeat variants (Schoustra et al., 2019). The $\mathrm{TR}_{46}^{3}$ variant has also been found in Dutch clinical isolates since 2012 (Zhang et al., 2017). We found low numbers of pan-azole resistant isolates in soils from cereal fields and no new azole-resistant genotypes were identified. However, TR $46 / \mathrm{Y} 121 \mathrm{~F} / \mathrm{M} 172 \mathrm{I} / \mathrm{T} 289 \mathrm{~A} / \mathrm{G} 448 \mathrm{~S}$ and $\mathrm{TR}_{46} / \mathrm{Y} 121 \mathrm{~F} / \mathrm{T} 289 \mathrm{~A} / \mathrm{S} 363 \mathrm{P} / \mathrm{I} 364 \mathrm{~V} / \mathrm{G} 448 \mathrm{~S}$, a novel CYP51A variant not reported before, were found in aerosols sampled at two urban locations in the Netherlands, indicating that new pan-azole resistant genotypes are evolving in habitats other than cereals, which can be regarded as a coldspot.

The latest report of a clinical case of infection with an azole resistant $A$. fumigatus strain carrying F46Y/M172V/E427K that acquired a 120-bp tandem repeat during long-term azole treatment, shows that the TR-mediated resistance mechanism is not restricted to environmental isolates only (Hare et al., 2019). In addition, the recent findings of airborne transmission of $A$. fumigatus by patients through coughs and sputum shows that not only spread of resistance mechanisms from environmentto-patient should be considered but also the spread from patient-to-environment and patient-to-patient (Lemaire et al., 2018; Engel et al., 2019). The origin of $\mathrm{TR}_{34}$ and $\mathrm{TR}_{46}$ based resistance mechanisms might be difficult to determine, however, the evolution of fungicide resistance is a continuous process in both clinical and environment settings where no borders exist for 
A. fumigatus. Monitoring the presence and dynamics of alleles linked with resistance to azole, MBC, QoI, and SDHI in $A$. fumigatus populations will be useful to identify hotspots and coldspots for resistance development in the wider environment. Measures to reduce inoculum build-up, to prevent dispersal and minimize resistance development using tailored fungicide resistance management strategies can then be introduced and validated. A one-health approach, taking into account the relationship between health and disease at the human, animal and environment interfaces, will be needed to tackle the further spread of antifungal resistance and to safeguard the value of azoles for both human health and food security.

\section{DATA AVAILABILITY STATEMENT}

The original contributions presented in the study are included in the article/Supplementary Material, further inquiries can be directed to the corresponding author/s.

\section{AUTHOR CONTRIBUTIONS}

$\mathrm{BF}$ and $\mathrm{AM}$ designed the experiments. $\mathrm{SA}, \mathrm{BF}$, and $\mathrm{SH}$ performed the experiments. $\mathrm{BF}$ and $\mathrm{SH}$ analyzed the data. BF, $\mathrm{AM}$, and JL participated in writing and/or editing the manuscript. All authors contributed to the article and approved the submitted version.

\section{FUNDING}

This work was supported by Crop Life International (grant 14209). BF received funding from the Newton Fund through

\section{REFERENCES}

Abdolrasouli, A., Rhodes, J., Beale, M. A., Hagen, F., Rogers, T. R., Chowdhary, A., et al. (2015). Genomic context of azole resistance mutations in Aspergillus fumigatus determined by using whole-genome sequencing. MBio 6:e00536. doi: 10.1128/mBio.00939-15

Ahangarkani, F., Puts, Y., Nabili, M., Khodavaisy, S., Moazeni, M., Salehi, Z., et al. (2020). First azole-resistant Aspergillus fumigatus with the environmental TR46/Y121F/T289A mutation in Iran. Mycoses 63, 430-436. doi: $10.1111 / \mathrm{myc} .13064$

Bader, O., Tünnermann, J., Dudakova, A., Tangwattanachuleeporn, M., Weig, M., and Groß, U. (2015). Environmental isolates of azole-resistant Aspergillus fumigatus in Germany. Antimicrob. Agents Chemother. 59, 4356-4359. doi: 10.1128/AAC.00100-15

Balajee, S. A., Tay, S. T., Lasker, B. A., Hurst, S. F., and Rooney, A. P. (2007). Characterization of a novel gene for strain typing reveals substructuring of Aspergillus fumigatus across North America. Eukaryot. Cell 6, 1392-1399. doi: 10.1128/EC.00164-07

Berger, S., Chazli, Y. E., Babu, A. F., and Coste, A. T. (2017). Azole resistance in Aspergillus fumigatus: a consequence of antifungal use in agriculture? Front. Microbiol. 8:1024. doi: 10.3389/fmicb.2017.01024

Bromley, M. J., van Muijlwijk, G., Fraczek, M. G., Robson, G., Verweij, P. E., Denning, D. W., et al. (2014). Occurrence of azole-resistant species of Aspergillus in the UK environment. J. Glob. Antimicrob. Resist. 2, 276-279. doi: 10.1016/j.jgar.2014.05.004

Buied, A., Moore, C. B., Denning, D. W., and Bowyer, P. (2013). High-level expression of cyp51B in azole-resistant clinical Aspergillus fumigatus isolates. J. Antimicrob. Chemother. 68, 512-514. doi: 10.1093/jac/dks451 grant BB/S018867/2 awarded by Biotechnology and Biological Sciences research Council (BBSRC) of the UK under the BBSRCFAPESP AMR and Insecticide Pest Resistance in Livestock and Agriculture Programme. Rothamsted Research receives strategic funding from the BBSRC. The Rothamsted Long-term Experiments National Capability was supported by BBSRC Grant $\mathrm{BBS} / \mathrm{E} / 00005198$. The funders played no role in the design of the study, the collection, analysis, or interpretation of data, or in writing the manuscript.

\section{ACKNOWLEDGMENTS}

We thank all members of Scientific Advisory Board (SAB) consisting of representatives of the Agrochemical Industry [Dr. Martin Semar (BASF), Dr. Klaus Stenzel and Dr. Andreas Goertz (Bayer CropScience), and Dr. Helge Sierotzki (Syngenta)] and experts from the A. fumigatus research community [Prof. Paul Verweij (Radboud University Medical Centre, The Netherlands), Prof. Paul Bowyer (University of Manchester), and Prof. Paul Dyer (University of Nottingham, UK)] for their valuable advice, support, and provision of samples. We also thank Dr. Jacques Meis (Canisius Wilhelmina Hospital, Nijmegen, The Netherlands) and Prof. Matt Fisher (Imperial College London, UK) for providing reference isolates and Ir. Peter Verkade for air sampling in Boskoop, The Netherlands.

\section{SUPPLEMENTARY MATERIAL}

The Supplementary Material for this article can be found online at: https://www.frontiersin.org/articles/10.3389/fmicb. 2020.599233/full\#supplementary-material

Buil, J. B., Hagen, F., Chowdhary, A., Verweij, P. E., and Meis, J. F. (2018) Itraconazole, voriconazole and posaconazole CLSI MIC distributions for wild-type and azole-resistant Aspergillus fumigatus isolates. J. Fungi. 4:103. doi: 10.3390/jof4030103

Camps, S. M. T., Dutilh, B. E., Arendrup, M. C., Rijs, A. J. M. M., Snelders, E., Huynen, M. A., et al. (2012a). Discovery of a hapE mutation that causes azole resistance in Aspergillus fumigatus through whole genome sequencing and sexual crossing. PLoS ONE 7:e50034. doi: 10.1371/journal.pone.0050034

Camps, S. M. T., Rijs, A. J. M. M., Klaassen, C. H. W., Meis, J. F., O'Gorman, C. M., Dyer, P. S., et al. (2012b). Molecular epidemiology of Aspergillus fumigatus isolates harboring the TR34/L98H azole resistance mechanism. J. Clin. Microbiol. 50, 2674-2680. doi: 10.1128/JCM.00335-12

Carter, H. E., Fraaije, B. A., West, J. S., Kelly, S., Mehl, A., Shaw, M. W., et al. (2014). Alterations in predicted regulatory and coding regions of the sterol. 14 $\alpha$-demethylase gene (CYP51) confer decreased azole sensitivity in the oilseed rape pathogen Pyrenopeziza brassicae. Mol. Plant Pathol. 15, 513-522. doi: $10.1111 / \mathrm{mpp} .12106$

Chowdhary, A., Kathuria, S., Xu, J., and Meis, J. F. (2013). Emergence of azole-resistant Aspergillus fumigatus strains due to agricultural azole use creates an increasing threat to human health. PLoS Pathog. 9:e1003633. doi: 10.1371/annotation/4ffcf1da-b180-4149-834c-9c723c5dbf9b

Chowdhary, A., Kathuria, S., Xu, J., Sharma, C., Sundar, G., Singh, P. K., et al. (2012). Clonal expansion and emergence of environmental multiple-triazoleresistant Aspergillus fumigatus strains carrying the TR34/L98H mutations in the cyp51A gene in India. PLoS ONE 7:e52871. doi: 10.1371/journal.pone.0052871

Chowdhary, A., and Meis, J. F. (2018). Emergence of azole resistant Aspergillus fumigatus and one health: time to implement environmental stewardship. Environ. Microbiol. 20, 1299-1301. doi: 10.1111/1462-2920.14055 
Cools, H. J., and Fraaije, B. A. (2013). Update on mechanisms of azole resistance in Mycosphaerella graminicola and implications for future control. Pest Manage Sci. 69, 150-155. doi: 10.1002/ps.3348

De Groot, T., and Meis, J. F. (2019). Microsatellite stability in STR analysis Aspergillus fumigatus depends on number of repeat units. Front. Cell. Infect. Microbiol. 9:82. doi: 10.3389/fcimb.2019.00082

De Valk, H. A., Meis, J. F. G. M., Curfs, I. M., Muehlethaler, K., Mouton, J. W., and Klaassen, C. H. W. (2005). Use of a novel panel of nine short tandem repeats for exact and high-resolution fingerprinting of Aspergillus fumigatus isolates. J. Clin. Microbiol. 43, 4112-4120. doi: 10.1128/JCM.43.8.4112-4120.2005

Denning, D. W., Venkateswarlu, K., Oakley, K. L., Anderson, M. J., Manning, N. J., Stevens, D. A., et al. (1997). Itraconazole resistance in Aspergillus fumigatus. Antimicrob. Agents Chemother. 41, 1364-1368. doi: 10.1128/AAC.41.6.1364

Duarte-Escalante, E., Frías-De-León, M. G., Martínez-Herrera, E., AcostaAltamirano, G., Rosas de Paz, E., Reséndiz-Sánchez, J., et al. (2020). Identification of CSP types and genotypic variability of clinical and environmental isolates of Aspergillus fumigatus from different geographic origins. Microorganisms 8:688. doi: 10.3390/microorganisms 8050688

Dunne, K., Hagen, F., Pomeroy, N., Meis, J. F., and Rogers, T. R. (2017). Intercountry transfer of triazole-resistant Aspergillus fumigatus on plant bulbs. Clin. Infect. Dis. 65, 147-149. doi: 10.1093/cid/cix257

Engel, T. G. P., Erren, E., Vanden Driessche, K. S. J., Melchers, W. J. G., Reijers, M. H., Merkus, P., et al. (2019). Aerosol transmission of Aspergillus fumigatus in cystic fibrosis patients in the Netherlands. Emerg Inf. Dis. 25, 797-799. doi: 10.3201/eid2504.181110

Förster, H., Kanetis, L., and Adaskaveg, J. E. (2004). Spiral gradient dilution, a rapid method for determining growth responses and 50\% effective concentration values in fungus-fungicide interactions. Phytopathology. 94, 163170. doi: 10.1094/PHYTO.2004.94.2.163

Fraaije, B. A., Bayon, C., Atkins, S., Cools, H. J., Lucas, J. A., and Fraaije, M. W. (2012). Risk assessment studies on succinate dehydrogenase inhibitors, the new weapons in the battle to control Septoria leaf blotch in wheat. Mol. Plant Pathol. 13, 263-275. doi: 10.1111/j.1364-3703.2011.00746.x

Fraczek, M. G., Bromley, M., and Bowyer, P. (2011). An improved model of the Aspergillus fumigatus CYP51A protein. Antimicrob Agents and Chemother. 55, 2483-2486. doi: 10.1128/AAC.01651-10

Fraczek, M. G., Bromley, M., Buied, A., Moore, C. B., Rajendran, R., Rautemaa, R., et al. (2013). The crd1B efflux transporter is associated with non-cyp51amediated itraconazole resistance in Aspergillus fumigatus. J. Antimicrob. Chemother. 68, 1486-1496. doi: 10.1093/jac/dkt075

Garcia-Rubio, R., Alcazar-Fuoli, L., Monteiro, M. C., Monzon, S., Cuesta, I., Peleaz, T., et al. (2018). Insight into the significance of Aspergillus fumigatus cyp51A polymorphisms. Antimicrob. Agents Chemother. 62:e00241. doi: 10.1128/AAC.00241-18

Gisi, U. (2014). Assessment of selection and resistance risk for demethylation inhibitor fungicides in Aspergillus fumigatus in agriculture and medicine: a critical review. Pest Manage Sci. 70, 352-364. doi: 10.1002/ps.3664

Gisi, U., Sierotzki, H., Cook, A., and McCaffery, A. (2002). Mechanisms influencing the evolution to Qo inhibitor fungicides. Pest Manage Sci. 58, 859-867. doi: $10.1002 /$ ps.565

Hagiwara, D., Arai, T., Takahashi, H., Kusuya, Y., Watanabe, A., and Kamei, K. (2018). Non-cyp51A azole-resistant Aspergillus fumigatus isolates with mutation in HMG-CoA reductase. Emerging Infect. Dis. 24, 1889-1897. doi: 10.3201/eid2410.180730

Hagiwara, D., Watanabe, A., Kamei, K., and Goldman, G. H. (2016). Epidemiological and genomic landscape of azole resistance mechanisms in Aspergillus fungi. Front. Microbiol. 7:1382. doi: 10.3389/fmicb.2016. 01382

Hare, R. K., Gertsen, J. B., Astvad, K. M. T., Degn, K. B., Løkke, A., Stegger, M., et al. (2019). In vivo selection of a unique tandem repeat mediated azole resistance mechanism (TR120) in Aspergillus fumigatus cyp51A, Denmark. Emerg. Infect. Dis. 25, 577-580. doi: 10.3201/eid2503.180297

Hawkins, N. J., and Fraaije, B. A. (2016). Predicting resistance by mutagenesis: lessons from. 45 years of MBC resistance. Front. Microbiol. 7:1814. doi: $10.3389 /$ fmicb. 2016.01814

Hawkins, N. J., and Fraaije, B. A. (2018). Fitness penalties in the evolution of fungicide resistance. Annu. Rev. Phytopathol. 56, 339-360. doi: 10.1146/annurev-phyto-080417-050012
Hollomon, D. (2017). Does agricultural use of azole fungicides contribute to resistance in the human pathogen Aspergillus fumigatus? Pest Manage Sci. 73, 1987-1993. doi: 10.1002/ps.4607

Howard, S. J., Cerar, D., Anderson, M. J., Albarrag, A., Fisher, M. C., Pasqualotto, A. C., et al. (2009). Frequency and evolution of azole resistance in Aspergillus fumigatus associated with treatment failure. Emerging Infect. Dis. 15, 1068-1076. doi: 10.3201/eid1507.090043

Kidd, S. E., Goeman, E., Meis, J. F., Slavin, M. A., and Verweij, P. (2015). Multitriazole-resistant Aspergillus fumigatus infections in Australia. Mycoses 58, 350-355. doi: 10.1111/myc. 12324

Kidd, S. E., Nik Zulkepeli, N. A. A., Slavin, M. A., and Morrissey, C. O. (2009). Utility of a proposed CSP typing nomenclature for Australian Aspergillus fumigatus isolates: Identification of additional CSP types and suggested modifications. J. Microbiol. Methods 78, 223-226. doi: 10.1016/j.mimet.2009.06.003

Klaassen, C. H. W., de Valk, H. A., Balajee, S. A., and Meis, J. F. G. M. (2009). Utility of CSP typing to sub-type clinical Aspergillus fumigatus isolates and proposal for a new CSP type nomenclature. J. Microbiol. Methods 77, 292-296. doi: 10.1016/j.mimet.2009.03.004

Klaassen, C. H. W., Gibbons, J. G., Fedorova, N. D., Meis, J. F., and Rokas, A. (2012). Evidence for genetic differentiation and variable recombination rates among Dutch populations of the opportunistic human pathogen Aspergillus fumigatus. Mol. Ecol. 21, 57-70. doi: 10.1111/j.1365-294X.2011.05364.x

Koenraadt, H., Somerville, S. C., and Jones, A. L. (1992). Characterisation of mutations in the $\beta$-tubulin gene of benomyl-resistant field strains of Venturia inaequalis and other plant pathogenic fungi. Phytopathology 82, 1348-1354. doi: 10.1094/Phyto-82-1348

Lavergne, R.-A., Morio, F., Favennec, L., Dominique, S., Meis, J. F., Gargala, G., et al. (2015). First description of azole-resistant Aspergillus fumigatus due to TR46/Y121F/T289A mutation in France. Antimicrob. Agents Chemother. 59, 4331-4335. doi: 10.1128/AAC.00127-15

Lazzarini, C., Esposto, M. C., Prigitano, A., Cogliati, M., De Lorenzis, G., and Tortorano, A. M. (2016). Azole resistance in Aspergillus fumigatus clinical isolates from an Italian culture collection. Antimicrob. Agents Chemother. 60, 682-685. doi: 10.1128/AAC.02234-15

Lemaire, B., Normand, A.-C., Forel, J.-M., Cassir, N., Piarroux, R., and Ranque, S. (2018). Hospitalized patient as source of Aspergillus fumigatus, 2015. Emerging Infect. Dis. 24, 1524-1527. doi: 10.3201/eid2408.171865

Liu, M., Zheng, N., Li, D., Zheng, H., Zhang, L., Ge, H., et al. (2016). Cyp51A-based mechanism of azole resistance in Aspergillus fumigatus: illustration by a new. 3D structural model of Aspergillus fumigatus CYP51A protein. Med. Mycol. 54, 400-408. doi: 10.1093/mmy/myv102

Macdonald, A., Poulton, P., Clark, I., Scott, T., Glendining, M., Perryman, S., et al. (2018). Guide to the Classical and Other Long-term experiments, Datasets and Sample Archive. (Harpenden, UK: Rothamsted Research).

Maertens, J. A. (2004). History of the development of azole derivatives. Clin. Microbiol. Infect. 10, 1-10. doi: 10.1111/j.1470-9465.2004.00841.x

Mair, W., Lopez-Ruiz, F., Stammler, G., Clark, W., Burnett, F., Hollomon, D., et al. (2016). Proposal for a unified nomenclature for target site mutations associated with resistance to fungicides. Pest Manage Sci. 8, 1449-1459. doi: $10.1002 / \mathrm{ps} .4301$

Meneau, I., Coste, A. T., and Sanglard, D. (2016). Identification of Aspergillus fumigatus multidrug transporter genes and their potential involvement in antifungal resistance. Med. Mycol. 54, 616-627. doi: 10.1093/mmy/myw005

Mullins, J. G. L., Parker, J. E., Cools, H. J., Martel, C. M., Togawa, R. C., Lucas, J. A., et al. (2011). Molecular modelling of the emergence of azole resistance in Mycosphaerella graminicola. PLoS ONE 6:e20973. doi: 10.1371/journal.pone.0020973

Peterson, S. W. (1992). Neosartorya pseudofischeri sp. nov. and its relationship to other species in Aspergilius section Fumigati. Mycol. Res. 96, 547-554. doi: 10.1016/S0953-7562(09)80979-9

Pong, R., Boost, M. V., O’Donoghue, M. M., and Appelbaum, P. C. (2010). Spiral gradient endpoint susceptibility testing: a fresh look at a neglected technique. J. Antimicrob. Chemother. 65, 1959-1963. doi: 10.1093/jac/ dkq239

Powlson, D. S., Glendining, M. J., Coleman, K., and Whitmore, A. P. (2011). Implications for soil properties of removing cereal straw: results from longterm studies. J. Agron. 103, 279-287. doi: 10.2134/agronj2010.0146s 
Rocchi, S., Daguindau, E., Grenouillet, F., Deconinck, E., Bellanger, A.-P., GarciaHermoso, D., et al. (2014). Azole-resistant Aspergillus fumigatus isolate with the TR34/L98H mutation in both a fungicide-sprayed field and the lung of a hematopoietic stem cell transplant recipient with invasive Aspergillosis. J. Clin. Microbiol. 52, 1724-1726. doi: 10.1128/JCM.03182-13

Rodriguez-Tudela, J. L., Alcazar-Fuoli, L., Mellado, E., Alastruey-Izquierdo, A., Monzon, A., and Cuenca-Estrella, M. (2008). Epidemiological cutoffs and cross-resistance to azole drugs in Aspergillus fumigatus. Antimicrob. Agents Chemother. 52, 2468-2472. doi: 10.1128/AAC.00156-08

Russell, P. E. (2005). A century of fungicide evolution. J. Agric. Sci. 143, 11-25. doi: 10.1017/S0021859605004971

Rybak, J. M., Ge, W., Wiederhold, N. P., Parker, J. E., Kelly, S. L., Rogers, P. D., et al. (2019). Mutations in hmg1, (2019) Challenging the paradigm of clinical triazole resistance in Aspergillus fumigatus. MBio 10:e00437. doi: $10.1128 / \mathrm{mBio} .00437-19$

Schoustra, S. E., Debets, A. J. M., Rijs, A. J. M. M., Zhang, J., Snelders, E., Leendertse, P. C., et al. (2019). Environmental hotspots for azole resistance selection of Aspergillus fumigatus, the Netherlands. Emerging Infect. Dis. 25, 1347-1353. doi: 10.3201/eid2507.181625

Sewell, T. R., Zhu, J., Rhodes, J., Hagen, F., Meis, J. F., Fisher, M. C., et al. (2019). Nonrandom distribution of azole resistance across the global population of Aspergillus fumigatus. MBio 10:e00392. doi: 10.1128/mBio.00392-19

Sierotzki, H., and Scalliet, G. (2013). A review of current knowledge of resistance aspects for the next-generation succinate dehydrogenase inhibitor fungicides. Phytopathology 103, 880-887. doi: 10.1094/PHYTO-01-13-0009-RVW

Snelders, E., Camps, S. M. T., Karawajczyk, A., Schaftenaar, G., Kema, G. H. J., van der Lee, H. A., et al. (2012). Triazole fungicides can induce crossresistance to medical triazoles in Aspergillus fumigatus. PLoS ONE 7:e31801. doi: 10.1371/journal.pone.0031801

Snelders, E., van der Lee, H. A. L., Kuijpers, J., Rijs, A. J. M. M., Varga, J., Samson, R. A., et al. (2008). Emergence of azole resistance in Aspergillus fumigatus and spread of a single resistance mechanism. PLoS Med. 5:e219. doi: 10.1371/journal.pmed.0050219

Steinmann, J., Hamprecht, A., Vehreschild, M. J. G. T., Cornely, O. A., Buchheidt, D., Spiess, B., et al. (2015). Emergence of azole-resistant invasive aspergillosis in HSCT recipients in Germany. J. Antimicrob. Chemother. 70, 1522-1526. doi: $10.1093 / \mathrm{jac} / \mathrm{dku} 566$

Tsitsopoulou, A., Posso, R., Vale, L., Bebb, S., Johnson, E., and White, P. L. (2018). Determination of the prevalence of triazole resistance in environmental Aspergillus fumigatus strains isolated in South Wales, UK. Front. Microbiol. 9:1395. doi: 10.3389/fmicb.2018.01395
Van der Linden, J. W. M., Snelders, E., Kampinga, G. A., Rijnders, B. J., Mattsson, E., Debets-Ossenkopp, Y. J., et al. (2011). Clinical implications of azole resistance in Aspergillus fumigatus, the Netherlands, 20072009. Emerging Infect. Dis. 10, 1846-1854. doi: 10.3201/eid1710.1 10226

van Ingen, J., van der Lee, H. A., Rijs, T. A., Zoll, J., Leenstra, T., Melchers, W. J. G., et al. (2015). Azole, polyene and echinocandin MIC distributions for wild-type, TR34/L98H and TR46/Y121F/T289A Aspergillus fumigatus isolates in the Netherlands. J. Antimicrob. Chemother. 70, 178-181. doi: 10.1093/jac/ dku364

Verweij, P. E., Chowdhary, A., Melchers, W. J. G., and Meis, J. F. (2016). Azole resistance in Aspergillus fumigatus: can we retain the clinical use of mold-active antifungal azoles? Clin. Infect. Dis. 62, 362-368. doi: 10.1093/cid/civ885

Verweij, P. E., Snelders, E., Kema, G. H. J., Mellado, E., and Melchers, W. J. G. (2009). Azole resistance in Aspergillus fumigatus: a sideeffect of environmental fungicide use? Lancet Infect. Dis. 9, 789-795. doi: 10.1016/S1473-3099(09)70265-8

Wei, X., Chen, P., Gao, R., Li, Y., Zhang, A., Liu, F., et al. (2017). Screening and characterization of a non-cyp51A mutation in an Aspergillus fumigatus cox10 strain conferring azole resistance. Antimicrob. Agents Chemother. 61:e0210116. doi: 10.1128/AAC.02101-16

Wiederhold, N. P., Gil, V. G., Gutierrez, F., Lindner, J. R., Albataineh, M. T., McCarthy, D. I., et al. (2016). First detection of TR34 L98H and TR46 Y121F T289A cyp51 mutations in Aspergillus fumigatus isolates in the United States. J. Clin. Microbiol. 54, 168-171. doi: 10.1128/JCM.02478-15

Zhang, J., Snelders, E., Zwaan, B. J., Schoustra, S. E., Meis, J. F., van Dijk, K., et al. (2017). A novel environmental azole resistance mutation in Aspergillus fumigatus and a possible role of sexual reproduction in its emergence. MBio 8:e00791-17. doi: 10.1128/mBio.00791-17

Conflict of Interest: The authors declare that the research was conducted in the absence of any commercial or financial relationships that could be construed as a potential conflict of interest.

Copyright (c) 2020 Fraaije, Atkins, Hanley, Macdonald and Lucas. This is an openaccess article distributed under the terms of the Creative Commons Attribution License (CC BY). The use, distribution or reproduction in other forums is permitted, provided the original author(s) and the copyright owner(s) are credited and that the original publication in this journal is cited, in accordance with accepted academic practice. No use, distribution or reproduction is permitted which does not comply with these terms. 